\title{
ENSAYO DE SISTEMATIZACIÓN DE LA CERÁMICA IBÉRICA PROCEDENTE DE LAS NECRÓPOLIS DE ALMEDINILLA, CÓRDOBA
}

\author{
DESIDERIO VAQUERIZO GIL \\ Seminario de Arqueología. Universidad de Córdoba
}

\begin{abstract}
Como avance de su Tesis Doctoral, presentada en la Universidad de Córdoba en 1987, el autor ofrece una ordenación tipológica del material cerámico que componía los ajuares funerarios de los 253 enterramientos exhumados por L. Maraver (en 1867) en la necrópolis de «Los Collados» (Almedinilla, Córdoba). Dicho material se halla actualmente muy disperso y, en este sentido, el trabajo que sigue trata por encima de todo de ofrecer a la investigación un corpus global de fácil consulta. Destaca, como conclusión cronológica, la fijación del período de utilización de la necrópolis entre fines del s. V a.C. y mediados del III, si bien es posible acotar su momento de máximo esplendor en la primera mitad del s. IV a.C.

As an advance of his Doctoral Dissertation, presented at the University of Cordoba in 1987, the author presents a tipology of the pottery that composed the furnitures of the 253 burials excavated by L. Maraver (in 1867) in the «Los Collados» Necropolis (Almedinilla, Córdoba). The finds are actually very dispersed and, in this sense, the work that follows tryes principaly to offer to the investigation a general «corpus» susceptible of be consulted with facility. It's important, as a chronological conclusion, the establishing of the utilization period of the necropolis from the later 5th. century B.C. to middle 3 rd. century B.C.; being his most important period the first half of the 4th. century B.C.
\end{abstract}

Como resulta habitual en el panorama de las necrópolis ibéricas de la Alta Andalucía, las necrópolis de Almedinilla deben ser estudiadas con grandes limitaciones debido a las circunstancias que rodearon su descubrimiento, lo que no quita que, en bloque, constituyan, tanto por la entidad de sus restos constructivos como por la riqueza de los ajuares, uno de los conjuntos más interesantes de toda el área ibérica.
En lo que respecta a la época ibérica, son dos las necrópolis que conocemos:

A) Los Collados: De ella tan sólo sabemos (MARAVER, 1867 a y b) que los enterramientos estaban distribuidos de forma arbitraria e indeterminada, en algunos sitios muy apiñados y confundidos (lo que nos sugiere la posible existencia de superposiciones); que, por lo general, se hallaban a 
una profundidad media de 0 ' $5 \mathrm{~m}$.; que todos ellos eran de incineración a excepción de tres, «encerrados en sepulcros, formados de grandes losas cuidadosamente colocadas» (1); que existían tumbas de enterramiento individual y múltiple, conteniendo habitualmente entre tres y siete vasos cerámicos; que la mayor parte de los objetos de ajuar aparecieron dentro de las urnas, entre los huecos, a excepción de las armas; que apenas se constataron restos de ustrina, a diferencia de lo que ocurría en los Torviscales (Fuente Tójar) y que fueron excavados 253 enterramientos en el plazo récord de ocho días. Nada sabemos acerca de la asociación ajuar/tumba; de la disposición de aquél dentro de ésta; de su mayor o menor riqueza o de la morfología exacta de las incineraciones.

B) Cerro de la Cruz: En la Memoria que P. Paris y A. Engel nos legaron acerca de sus excavaciones en torno al núcleo urbano de Almedinilla, nos hablan, sorprendentemente, de una necrópolis en la propia ladera del Cerro de la Cruz, «a derecha e izquierda de la capilla» (PARIS, ENGEL, 1906, 56), lo que quiere decir a escasos metros de la excavación practicada por nosotros en 1985. Los mismos arqueólogos franceses debieron extrañarse de tal circunstancia, pues tienen buen cuidado de resaltar que esta necrópolis no debe ser confundida con la de Maraver. No obstante, a pesar de ello sólo nos dicen que los restos del cadáver aparecían en el interior de urnas rotas casi siempre por la presión y la acción química de las tierras, colocadas al abrigo de algunas rocas que afloraban a la superficie. Se nos habla también de un gran número de ellas, pero su excavación se abandonó por proporcionar restos de escaso interés y «parce que la céramique de ce cimètiere... appartient toute au même époque et qu'elle n'avant plus grand chose a nous apprendre».

(1) La interpretación socio-cultural de los tipos de tumba exhumados en las necrópolis ibéricas de Almedinilla, así como el estudio sistemático de todos sus materiales -en unión de la primera campaña de excavación arqueológica sistemática practicada en el poblado bajo nuestra dirección- son temas desarrollados en nuestra Tesis Doctoral, que, con el título A proximación al fenómeno de la Cultura Ibérica en el Sureste de la actual provincia de Córdoba: El yacimiento del Cerro de la Cruz (Almedinilla), fue presentada en la Universidad de Córdoba, bajo la dirección de la Prof. Dra. Pilar LEON ALONSO, en noviembre de 1987. Dicha Tesis ha sido publicada íntegramente en microficha por el Servicio de Publicaciones de la Universidad de Córdoba.
Esta cerámica no es diferenciada en el inventario de la recuperada en la excavación del poblado como tal, ni aparece reseñada en ningún museo español, conservándose tan sólo parcialmente en el Musée des Antiquités Nationales de Francia, donde consta con la única referencia de «Cerro de la Cruz, Almedinilla».

Por esta razón, el trabajo que presentamos incluye únicamente los materiales con reseñas seguras conservados en la actualidad en el Museo Arquelógico Provincial de Córdoba y en el Museo Arqueológico Nacional (2) y aquellas piezas del museo francés que aportan alguna novedad morfológica, y va, por tanto, referido a conjuntos que en todos los casos nos han llegado sin ningún tipo de referencias contextuales.

Establecer una tipología resulta siempre una tarea bastante arriesgada, al no poder prescindir de elementos de valoración subjetivos que, por esta misma razón, suelen ser fácilmente refutables. Aún así, en el caso que nos ocupa, pensamos que la única manera de acometer el estudio detallado del material consistía en un sistema de agrupación formal que reuniera las piezas en lotes diferenciables con facilidad y, sobre todo, que agilizara su estudio, favoreciendo en definitiva un acceso rápido y cómodo a sus áreas de dispersión y a su espectro cronológico.

Nuestro objetivo no ha sido, pues, elaborar una tipología de las formas más usuales constatadas entre la cerámica ibérica que deba o pueda ser utilizada como referencia para otros estudios relativos a este mismo período cultural. Por el contrario, hemos pretendido realizar, por encima de todo, un corpus funcional de cara a nuestro trabajo $y$, en este sentido, no dudamos que resulta, a todas luces, perfectible.

Para evitar la excesiva proliferación de grupos, tipos, subtipos, variantes y subvariantes, hemos decidido integrar el conjunto total de piezas en tres grandes grupos - susceptibles de ser ampliados, en el caso hipotético de que aparezca algún tipo no integrado en cualquiera de ellos- determinados por un elemento escogido al azar pero que consideramos predominante en el aspecto formal de la pieza:

(2) Desde aquí, nuestro agradecimiento al personal de ambos centros, en especial a Dña. Ana M. ${ }^{a}$ Vicent y D. Alejandro Marcos, en el primero, y a Dña. Alicia Rodero y D. Ricardo Olmos en el segundo. 
su perfil. Así, distinguimos un Grupo 1 en el que se incluyen todos aquellos vasos cuyo galbo presenta una tendencia globular más o menos acusada - por supuesto, conscientes de su hetereogeneidad y sin tomar en cuenta ningún determinante cronológico-; un Grupo 2 que acoge las piezas con galbos de tendencia cilíndrica, y, por fin, un Grupo 3 en el que integramos toda la variada tipología de platos, cuencos, páteras o tapaderas, cuyo contorno suele presentar un aspecto semiesférico más o menos pronunciado.

Dentro de cada grupo señalaremos los diferentes tipos existentes estableciendo como parangón la pieza que consideramos más sencilla (por ejemplo, en el caso del Tipo 1 aquélla que presenta los rasgos más ortodoxos, los que responden con mayor exactitud a la definición del tipo) (3); a continuación, distinguiremos, cuando existan, las variantes que puedan fijarse, considerando como tales aquéllas que presenten alguna modificación en las constantes básicas: orientación del borde - su morfología, dada su extraordinaria variedad, no siempre se puede considerar como determinante-, forma del cuello, galbo o base; y, por último, fijaremos cinco tipos básicos de subvariantes, que pueden o no darse en cada grupo de piezas y que por lo general -a excepción del Grupo 1/Tipo 1, en el que se establecen de forma indeterminada- se indicarán en cada variante.

Dichas subvariantes se fundamentan en el tipo de decoración, apreciándose así cinco posibilidades:

a) Decoración pintada monócroma que cubre toda la superficie.

(3) A veces, consideramos como un mismo Tipo formas relativamente diversas que, a su vez, pueden ser agrupadas entre sí por su mayor uniformidad (véase lo que ocurre por ejemplo en el Grupo I con los Tipos II, V y VI). En este caso, la descripción del prototipo la haremos de forma genérica y no fijaremos como parangón del mismo ninguna pieza concreta, sino que directamente las dividiremos por Variantes -que constituirán, a su vez, el modelo básico de un grupo mayor de vasos - y, en caso de que existan piezas similares aunque diferenciables por alguna de las que hemos llamado «constantes básicas», distinguiremos entre Variantes $\mathbf{A} / 1$, $\mathrm{A} / 2$, etc.

El grupo lo designaremos mediante número árabe, el tipo mediante números romanos, las Variantes por letras mayúsculas y las Subvariantes por letras minúsculas.

Finalmente, las piezas conservadas en el Museo de Córdoba serán designadas con su número de registro precedido de C-, las del Arqueológico Nacional irán precedidas de M.A.N.- y las del museo galo serán designadas previamente como PA-. b) Decoración pintada monócroma dispuesta en bandas concéntricas de más o menos anchura.

c) Decoración pintada polícroma (más de un color) dispuesta en bandas concéntricas.

d) Decoración pintada monócroma que incorpora, además de las bandas, motivos geométricos diversos (semicírculos concéntricos, cuartos de círculo, «aguas», segmentos concéntricos, etc.).

e) Decoración pintada polícroma, con bandas $\mathrm{y}$ motivos geométricos.

Pasamos así a la descripción de los tipos y variantes de cada grupo, incluyendo a continuación, en cada caso, un análisis más o menos detallado de su dispersión y cronología.

\section{GRUPO 1}

\section{TIPO I (Fig. 1)}

Formas cerradas; de perfil con tendencia globular; bordes exvasados, muy variados en cuanto a su morfología; cuello estrangulado, prácticamente inexistente, y base con ónfalo, a veces con el pie apenas indicado (números C-132, 133, 134, 153, 154, $161,163,174,186,212$ у 220) (4).

Podemos distinguir 6 variantes:

Variante A: Borde apenas exvasado, engrosado, que supone casi una simple continuación del galbo. Suele ser de tamaño inferior al resto de las piezas (números C-206, 207 y 247).

Variante B: Hombro carenado (números C-159 y 160).

Variante C: Perfil de tendencia bitrococónica (números C-158, 175 y 210).

Variante D: Con pie levemente indicado (números C-203 y 219).

Variante E: Hombro carenado y galbo de tendencia bitroncocónica (números C-155, 157, 162 y 202).

Variante F: Hombro carenado, galbo con tendencia bitroncocónica y pie indicado (números $\mathrm{C}$ 218 y 209).

(4) En este caso, ante la acusada abundancia de variantes y la escasa representatividad de las formas pintadas, en la Tabla Tipológica indicamos las subvariantes existentes (no se conserva ningún ejemplar decorado mediante bandas monócromas) de forma independiente a la Variante a que pertenecen, a efectos meramente ilustrativos. 


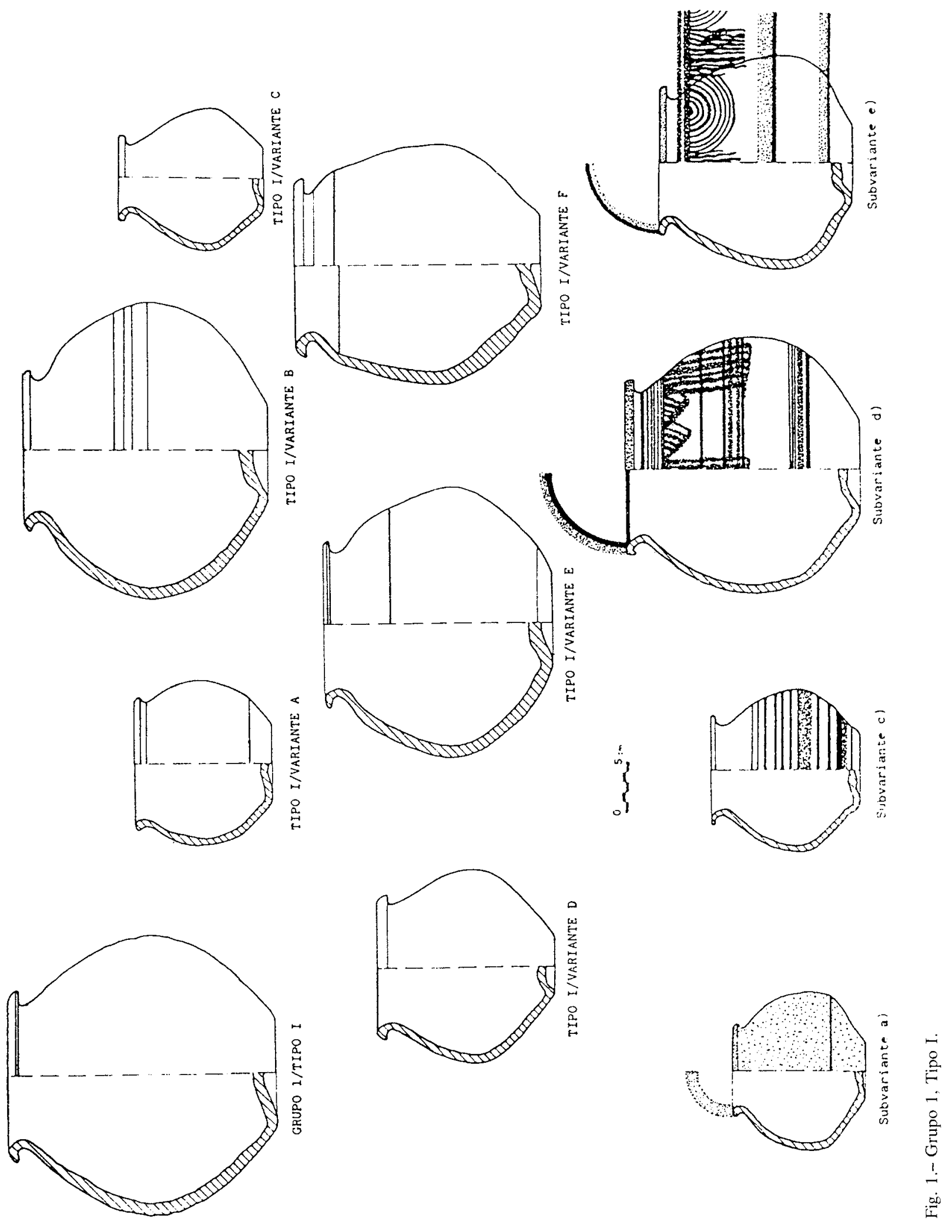


En total, se incluyen en este grupo 33 piezas que, de 162 conservadas -incluyendo la totalidad de las custodiadas en París, cuya procedencia de las necrópolis, según ya hemos indicado, no nos parece segura-, suponen, por tanto, un $20^{\prime} 37 \%$. De entre ellas, presentan decoración 5 ejemplares, es decir, un $15,5 \%$ del parcial. La decoración es polícroma en todos los casos excepto en uno.

Este tipo de piezas, cuyos caracteres morfológicos básicos se vienen repitiendo casi desde la aparición de la cerámica hasta nuestros días, constituye, con diferencia, el grupo más numeroso entre los vasos conservados en Almedinilla, pero resulta muy poco significativo a efectos cronológicos. Tan sólo la forma que incluimos como Variante $\mathrm{C}$ ha sido objeto de un estudio tipológico más o menos detallado (JULLY, NÖRDSTROM, 1972, 93 ss; JULLY, 1975, 48 ss, Figs. 33 a 42); puede relacionarse con la «jarra bitrococónica» de origen languedociense, en la que se distinguen tres variantes, $\mathrm{A}, \mathrm{B}$ y C, según ambas mitades sean aproximadamente de la misma altura; la superior más alta que la inferior, o ésta más alta que aquélla. La primera, más antigua, presenta una cronología enmarcable entre finales del siglo VI y el V a.C.; la B, muy extendida en la Península, se fecha entre los siglos V y III a.C. y la $C$, en ningún caso resulta anterior al siglo IV (JULLY, 1975, 48 ss).

$\mathrm{Al}$ margen de estas consideraciones, formas similares a las que constituyen nuestro tipo se pueden citar en la necrópolis de Los Torviscales (5); la Bobadilla (6); Tutugi (7); Toya (8); Castellones de

(5) MARCOS, VICENT, 1983, 11 ss: Tanto entre el material antiguo como entre el excavado recientemente por estos autores, en el Museo Arqueológico de Córdoba se conservan abundantes piezas de forma globular, bordes exvasados y cuello estrangulado, lisas y decoradas, que, por lo general, resulta difícil diferenciar de las de Almedinilla. La cronología de esta necrópolis es fijada, de acuerdo con las últimas excavaciones, entre fines del siglo VI y mediados del IV a.C.

VAQUERIZO, 1986, 360, Fig. 1,1.

(6) MALUQUER, PICAZO, RINCON, 1973, 32: El tipo de piezas que nos ocupa aparece ampliamente representado en esta necrópolis, destacando por su similitud formal el Tipo $\mathrm{Vb}$. Por su relación con la Cámara $\mathrm{A}$, tumba de incineración en forma de cista, se fechan entre mediados del siglo VI y mediados del V. a.C.

(7) CABRE, MOTOS, 1920. Se trata de una forma muy abundante, aunque debido a la mala calidad del material gráfico, así como a su escasez, resulta imposible relacionarlas con tumbas completas. Vid. por ejemplo Lám. XIII, pg.
Ceal (9); Baria (10); La Guardia (11) o Baza (12), es decir, se tráta de un tipo cerámico prácticamente común a todas las necrópolis de la Alta Andalucía y cuya cronología, al menos en esta zona, se remonta como mínimo a fines del siglo VI a.C., perdurando hasta época romana.

\section{TIPO II (Fig. 2)}

Piezas de borde exvasado, redondeado, ligeramente apuntado, en forma de cabeza de ánade o labiado; cuello más o menos desarrollado, de tendencia acampanada y separado del cuerpo por un suave hombro, en ocasiones acusadamente marcado; galbo de tendencia globular, a veces casi bitroncocónica, y bases convexas, con alto ónfalo, sólo en algún caso con el pie insinuado. Aparecen con y sin decoración, si bien se observa que ésta predomina en las piezas de menor formato, en las que se dan las subvariantes a), b) y c). Con 12 ejemplares, supone un $7,4 \%$ del total de piezas conservadas.

En función esencialmente de su tamaño se pueden distinguir dos Variantes:

56: sepultura de la zona III; Lám. XIV, 1, sepultura 10, O Lám. XVI, 31 a 38.

(8) PEREIRA, 1979, 312 ss y 330 . Son clasificadas como Grupo 7 , dentro del cual, aparte de los ejemplares que van sin decoración, se da una preponderancia casi absoluta de la categoría decorativa monócroma con motivos geométricos. Su cronología podría remontarse hasta fines del siglo $\mathrm{V}$ a.C.

(9) BLANCO, 1960, 26 ss; Fig. 53. Este tipo de urnas se constata tanto en el Nivel II como en el IV de los señalados por Blanco. Al primero le asigna una cronología aproximada entre 425 y 350 a.C.; al segundo, de la primera mitad del siglo III.

CHAPA, PEREIRA, 1986, Fig. 1,2.

FERNANDEZ CHICARRO, 1955, Lám. I, 3 y 5.

(10) ALMAGRO GORBEA, 1984, 201 ss, Fig. 112. Se corresponden con el Tipo II fijado por la autora entre las urnas de incineración, muy abundante y con tal variedad de formas y perfiles que se establecen 12 variantes. Comienzan a utilizarse con frecuencia en el siglo III a.C., prolongándose su uso hasta el s. I a.C. No presentan decoración alguna.

(11) BLANCO, 1960, 31-34, Fig. 52,8. Tumba 19. Cronología: comienzos del siglo III a.C.

(12) PRESEDO, 1982, 293-294. Constituye el tipo más frecuente en Baza, ofreciendo multitud de variantes. Está fechado en las tumbas con cerámica ática a principios del siglo IV y aparece hasta el final de la necrópolis como elemento típico. En general, se corresponden con el tipo a) de Presedo, pero las distintas Variantes se pueden relacionar con otros Tipos como el b), el c): Fig. 79,1; el d): Fig. 109,1; el f): Fig. 24; el r): fig. 5,1 y 179,1, etc. 
Variante A: Gran envergadura y cuello muy desarrollado (longitud superior a $2 / 5$ de la altura total de la pieza) (números C-142 y 143).

-Variante $\mathrm{A} / 1$ : Con hombro muy marcado (número C-148).

- Variante A/2: Galbo de tendencia bitrococónica (número C-149).

No suelen presentar decoración, $y$, cuando ésta aparece, responde siempre a la subvariante a) (números C-150 y 217). No obstante, en algunos casos es muy posible que haya sido borrada por el fuerte lavado a que fueron sometidas las piezas.

Variante B: Menor tamaño y cuello menos desarrollado (longitud inferior a $2 / 5$ de la altura total de la pieza) (números C-205 y 172).

-Variante B/1: Hombro muy marcado y borde labiado (número C-713).

- Variante B/2: Hombro marcado, borde redondeado y pie ligeramente indicado (número C-141).

Muestran decoración pintada en todos los casos -a excepción del $n^{\circ} 172$, que tan sólo ofrece una banda impresa a ruedecilla - respondiendo a las subvariantes a) (número $\mathrm{C}$-185); b) (número $\mathrm{C}$ 176) y c) (números C-141 y 713).

Este tipo de piezas, muy características de Almedinilla, derivan de prototipos orientales y ofrecen una amplia dispersión. Los vasos que incluimos como variante A proceden posiblemente de las típicas piezas de borde «à chardon», cuyos orígenes han sido muy discutidos pero que, en general, pueden rastrearse por todo el Próximo Oriente desde fechas muy antiguas. Para J.J. Jully, el tipo es de origen sirio-fenicio y conoció en la Península un cierto favor, dando lugar a imitaciones locales que resultan especialmente ortodoxas en las necrópolis de la Alta Andalucía, caso de Almedinilla, en la que se pueden fechar entre fines del siglo $\mathrm{V}$ y principios del IV a.C. (JULLY, 1975, 32 ss; Figs. 5 a 13; Grupo A-II,1).

En Andalucía no se conocen vasos de este tipo con anterioridad al siglo VIII a.C., en que se documentan por primera vez en la necrópolis de Setefilla (AUBET, 1976, 14-16), Cruz del Negro y la Joya (BELEN, PEREIRA, 1982, 313 ss; Tipo II.2.B.a.1). Más tarde,. se extenderían por el interior y darían lugar al tipo de vaso característico de necrópolis como las de Almedinilla; Tutugi (CABRE, MOTOS, 1920, Lám. XVI, 1 y 5); Castellones de Ceal (13); Toya (14); La Guardia (BLANCO, 1959, 89 ss; Tumbas 5 y 6); La Bobadilla (MALU-
QUER, PICAZO, RINCON, 1973, Fig. 17); Baza (15); Carmona (BELEN, 1982, Fig 2,657-1; Fig. 3,660; Fig. 4,663-1 y Fig. 5,664-1) o los Torviscales (16).

La evolución de la forma resulta muy difícil de precisar, pero lo cierto es que ya en plena época ibérica su dispersión abarca incluso hasta el Sur de Francia y así se puede señalar también, por ejemplo, en la necrópolis de Ensèrune (Languedoc) (JANNORAY, 1949, Lám. XXII, Fig. 7); Cayla III de Mailhac (SOLIER, 1976-78) Grupo IV Forma 1,

(13) BLANCO, 1960, 26 ss, Fig. 53. En Castellones, el tipo que nos ocupa aparece por vez primera en el que Blanco cataloga como Nivel II, fechable entre el 425 y el 350 a.C. En dicho estrato se observan fundamentalmente formas semejantes a nuestra Variante B y una con el cuello más desarrollado y de tendencia acampanada que presagia ya la aparición de la Variante A. Por tanto, en Castellones la Variante B es anterior a la A, que se documenta ya plenamente formada en el Estrato III; asignable a la segunda mitad del siglo IV a.C., y continúa con idénticas características durante el Estrato IV, al que se atribuye una cronologia de principios del siglo III. Parece, pues, darse una clara evolución desde las piezas de cuello acampanado, medianamente desarrollado, a las de cuello alto y borde «à chardon», que tiene lugar entre fines del siglo $\mathrm{V}$ y comienzos del siglo III a.C.

(14) PEREIRA, 1979, Fig. VI,1,2,3 y 4. Fig. VIII,1.

Entre las cerámicas procedentes de Toya, este tipo de vasos es catalogado como Grupo 4, diferenciándolo con claridad de las piezas que imitan el modelo «à chardon» de manera más ortodoxa. Se distinguen también 2 tipos en función de su tamaño y su cronología se fija entre mediados del siglo IV y comienzos del III a.C.

(15) PRESEDO, 1982, 301, ss. Se corresponden con el tipo g) de Presedo, que aparece por ejemplo en las tumbas 56 (Fig. 67); 65 (Fig. 75); 132 (Fig. 156,1) o 155 (fig. 173), y su cronología se fija a fines del siglo $\mathrm{V}$ o principios del siglo IV. Existe una variedad de esta forma que aparece en tumbas muy profundas de fosas cavadas en la roca y que, en líneas generales, podría identificarse con nuestra Variante B (Tumba 94 , Fig. 110). Se trata de tumbas muy antiguas, lo que parece confirmar la prioridad temporal de la Variante B sobre la A.

(16) MARCOS, VICENT, 1983, 11 ss; Fig. 10.

Una forma muy evolucionada de nuestra Variante $A$, con pie muy alto, cuello prácticamente cilíndrico y borde vuelto, en visera, se encuentra entre las recuperadas por A. Marcos y A.M. Vicent en sus excavaciones de 1977 y 1980 . Aparece en compañía de otro vaso idéntico a nuestro prototipo. Tumba 5. Cronología: segunda mitad del siglo VI - mediados del siglo IV a.C.

Por otra parte, se ha atribuido a Almedinilla un vaso de estas características cuya única referencia es M.A.N., II-959. Sin embargo, pese a sus características formales similares, su decoración resulta del todo extraña a la que caracteriza la cerámica de Los Collados, por lo que consideramos esta atribución errónea (PELLICER, 1969, 90, Fig. 9,4). 

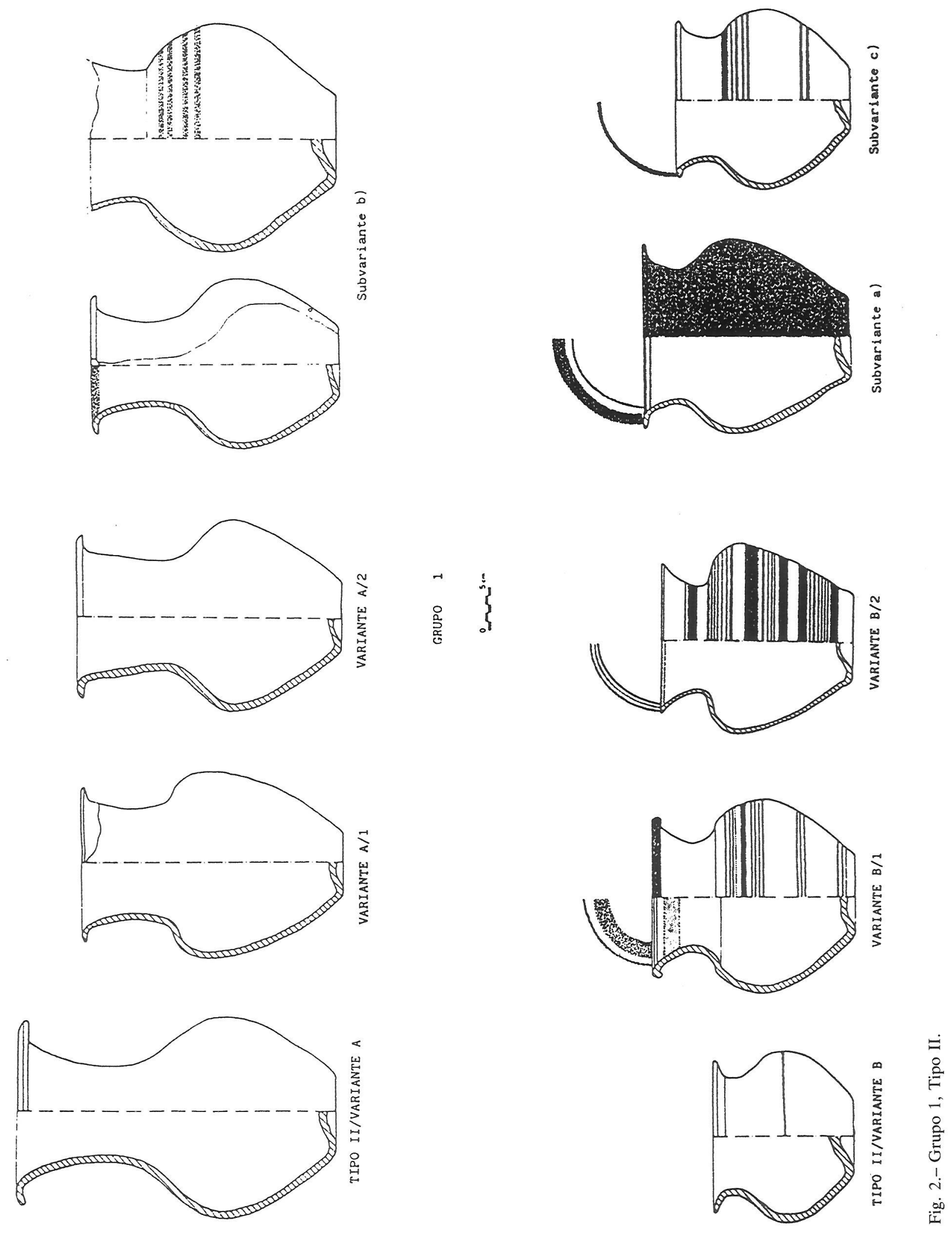

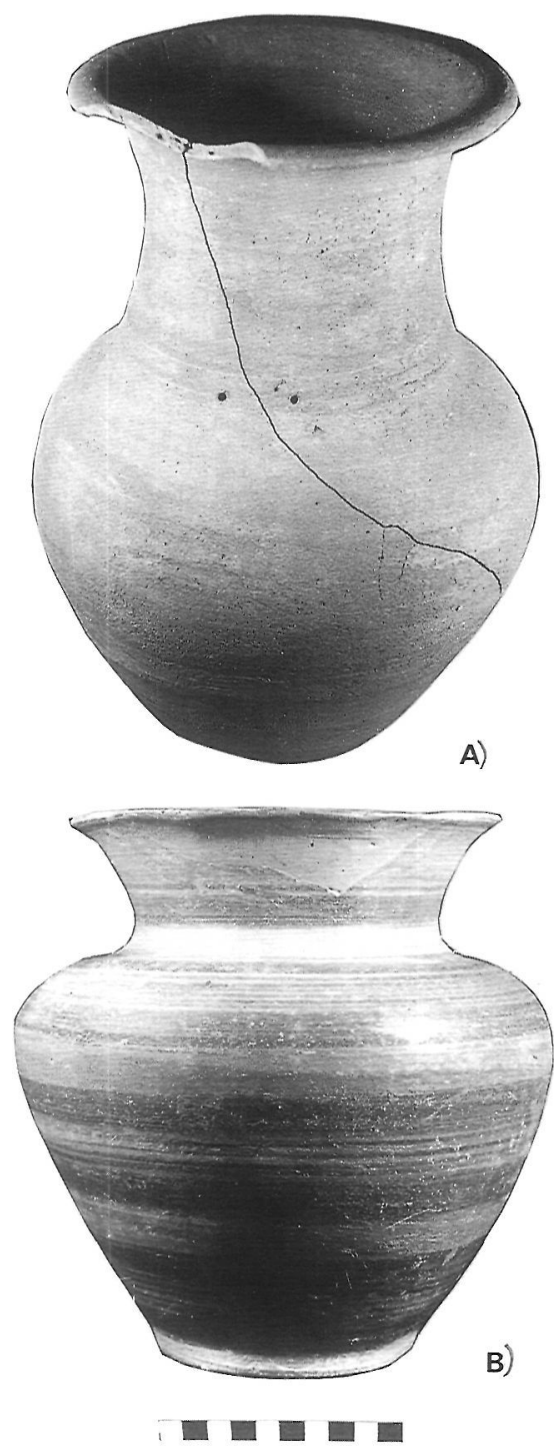

Lám. I:

A) GRUPO 1/TIPO II/VARIANTE A/Subvariante b).

B) GRUPO 1/TIPO II/VARIANTE B/2.

Figs. 30; 35; 36,1 y 37,3); Hoya de Santa Ana (Albacete) (SANCHEZ JIMENEZ, 1943, Lám. XIII); La Albufereta (Alicante) (RUBIO GOMIS, 1986, Tipo C, Fig. 146, C y Tipo G, Fig. 147, G); necrópolis de Orán (Argel) (SANTOS VELASCO, 1983, 320, Formaq VII, Fig. 2,6) o la propia Cartago (CINTAS, 1970, Vol., I, 330 ss, Lám. XXV.

Por otra parte, es preciso no olvidar el hondo paralelismo que estos vasos, en particular los de nuestra Variante B, presentan con muchas de las urnas, no siempre a torno, características de la Mese- ta y Cataluña. A este espíritu responden las piezas de las necrópolis de Agullana (PALOL, 1958, Fig. 79,4); Las Madrigueras (Carrascosa del Campo, Cuenca) (ALMAGRO-GORBEA, 1969, Tabla VIII. Tipos 2-2 y 2-3) o la recuperada en el poblado de Los Villares (Caudete de las Fuentes, Valencia) (GIL-MASCARELL, VALL, 1983, 451 ss).

La variante $B$, que en algunos yacimientos parece preceder a los grandes vasos que constituyen la Variante A, muestra una dispersión similar, constatándose piezas del mismo tipo además de en Castellones, Toya y Baza, en Cástulo, donde su cronología se puede remontar al siglo V a.C. (BLANCO, 1965, Figs. 2 y 14); Tutugi (CABRE, MOTOS, 1920, Lám. XVI,2); La Bobadilla (MALUQUER, PICAZO, RINCON, 1973, 39, Fig. 22); El Higuerón (FORTEA, BERNIER, 1970, Fig. 26,401); Castellones de Ceal (CHAPA, PEREIRA, 1986, 369 ss; Fig. 1,1); La Guardia (BLANCO, 1959, tumbas 4, 9 y 11); Los Patos (Cástulo) (BLAZQUEZ, 1975, Fig. 46,4); La Albufereta (RUBIO GOMIS, 1986, Fig. 146,D); Cerro Macareno (PELLICER, 1982, Nivel 12, Fig. 22,6; n. ${ }^{\circ}$ inv.: 1.462) o Pajar de Artillo (LUZON, 1973, Forma 1). Es catalogada además como Forma 20 entre la cerámica de «barniz rojo» (CUADRADO, 1969, 268, Fig. 10,20).

En su conjunto, el grupo de piezas que consideramos como Tipo II se constata preferentemente entre fines del s. V y principios del s. III a.C. No obstante, es preciso desechar el que algunos de los ejemplares de la Variante B, especialmente los polícromos, puedan ser remontados algo más atrás, $\mathrm{y}$, por otro lado, hay que señalar su perduración hasta el siglo I a.C., como puede apreciarse en el Pajar de Artillo, lo que nos da un espectro cronológico bastante dilatado.

\section{TIPO III (Fig. 3)}

Clasificamos en este tipo, muy emparentado con el anterior, los vasos de pequeño tamaño que designamos convencionalmente con el sobrenombre de «caliciformes». Ofrecen por lo común bordes redondeados y exvasados (entre los $45^{\circ}$ y los $60^{\circ}$ con respecto a la horizontal de la base), a veces diferenciados del cuello mediante una leve carena interior; cuello más o menos desarrollado y de tendencia acampanada, que da paso a través de un hombro carenado a un galbo de tipo globular; base generalmente con pie indicado y ónfalo marcado. Suelen ser piezas de paredes muy finas, elaboradas con pas- 

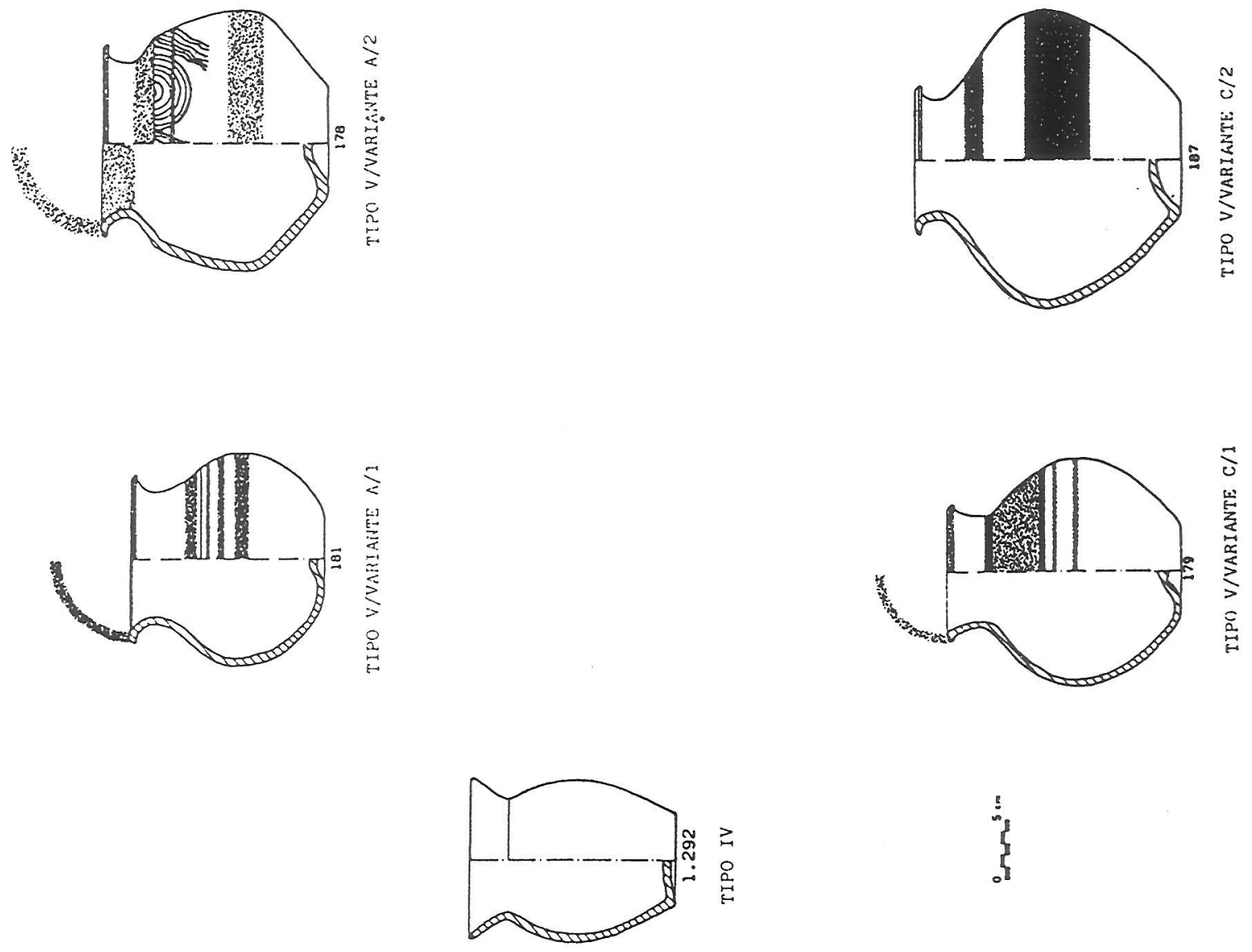

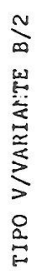
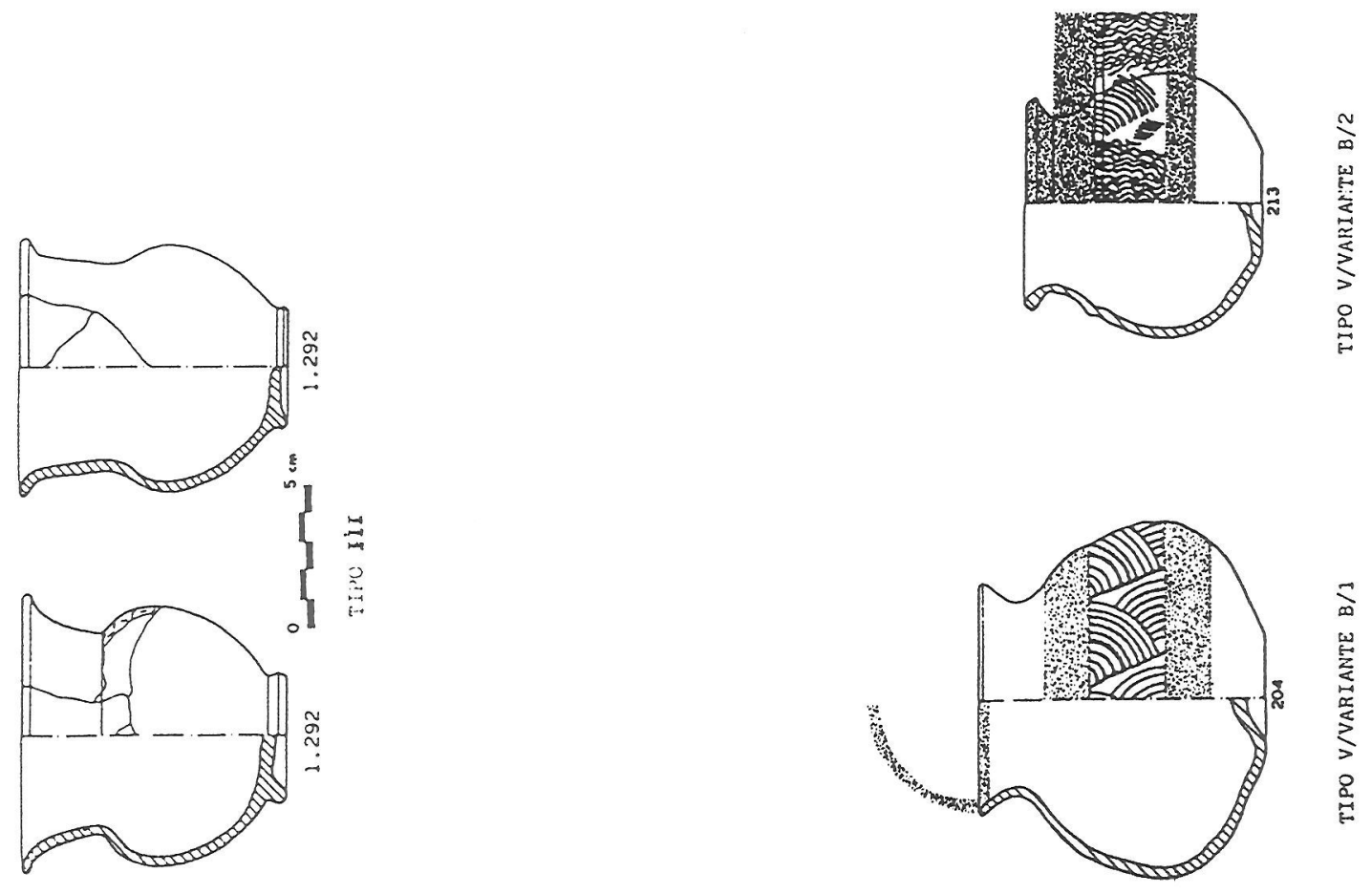

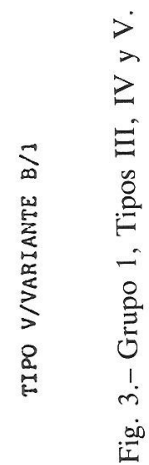


tas muy depuradas, de acabados perfectos y, en su conjunto, resultan de una gran uniformidad y elegancia, destacando por su falta de decoración (números PA-1.292 a y b).

Sólo se conservan tres ejemplares en París, es decir, un $1,85 \%$ del total, y es muy posible que procedan del poblado, no de la necrópolis.

Para J.J. Jully, quien analiza esta forma en el contexto fenicio-púnico del Mediterráneo Occidental, la cuestión de su origen debe ser afrontada desde dos puntos de vista diferentes, sin que exista una incompatibilidad real entre uno y otro, ya que se trataría de la convergencia de dos influencias: una mediterránea y otra itlohallstáttica. Habrían sido utilizados como vasos para beber y su cronología se situaría entre los siglos IV y III a.C. (JULLY, 1975, 52 ss; Figs. 43 a 45).

Para J.M. Luzón, sin embargo, quien cataloga este tipo de piezas en el Pajar de Artillo como Forma 3, se trata de la copia de un modelo helenístico de origen aqueménida, popularizado en el mundo griego a partir del siglo IV e implantado en la Península a partir del siglo III a.C. (LUZON, 1973, 39-40, Lám. IV).

Finalmente, según otros autores, existen dos grandes grupos de vasos que podríamos llamar caliciformes: el que da lugar a la vasija de barniz negro ático, procedente de una imitación de vasos metálicos asiáticos y propio del siglo IV, y otro más antiguo, fenicio, representado por los vasos «à chardon» (ARANEGUI, PLA, 1981, 81-82). De esta manera, el vaso caliciforme que aparece en la Península sería una derivación de los recipientes bitroncocónicos del momento de transición (siglos IV-III a.C.) entre las cerámicas grises más antiguas y los recipientes de pequeño tamaño más tardíos, relación evolutiva en la que el hecho de que el diámetro máximo de una pieza no sea superior a su altura le confiere una mayor modernidad (ARANEGUI, 1975, $366 \mathrm{ss})$.

En cualquier caso, el vaso caliciforme constituye un tipo cerámico que ofrece una dispersión extraordinaria y que, en lo relativo a su cronología, ofrece un amplio espectro de uso, debiendo remontarse al menos hasta finales del siglo IV a.C., aspecto en el que están de acuerdo cada vez más autores (ABAD, 1983, 194). Nos obstante, se trata de una forma que abunda de manera especial en los siglos III y II y que es muy frecuente entre los tesoros de plata correspondientes a los siglos II-I a.C.
(RADDATZ, 1969, 79 ss; FERNANDEZ GOMEZ, 1985, 182 ss; Figs. 14 y 15; Láms. VI, 1 y 2).

\section{TIPO IV (Fig. 3)}

Pequeño vaso de borde redondeado o apuntando, en todos los casos saliente, que forma en ocasiones un pequeño cuello de tendencia acampana$\mathrm{da}$, o bien da paso directamente y por medio de una acusada carena al galbo, de perfil casi piriforme; base plana, a veces marcando un ligero ónfalo, y paredes muy finas. En los casos constatados no presenta decoración (PA-1.292.c).

Sólo se conserva un ejemplar, que supone un $0,61 \%$ del total, y posiblemente procede también del poblado.

Se suelen denominar de forma convencional con el nombre genérico de «cubiletes» $\mathrm{y}$, sobre todo en el caso de los de dimensiones más reducidas, deben interpretarse como recipientes para sustancias especiales.

Se trata de un tipo de cerámica gris muy frecuente en la necrópolis de las Corts de Ampurias (si bien se fabricó también en barros más claros), que M. Almagro designa con el nombre de «toneletes» y considera de alguna manera precedente de las cerámicas que denominamos «de paredes finas». El modelo más antiguo es el más abierto por arriba y, en conjunto, se fechan entre comienzos del siglo III y comienzos del I a.C., momento en el que aparecen ya piezas decoradas con puntitos en relieve formando segmentos de círculos combinados que recuerdan la cerámica romana «a la barbotina» (ALMAGRO BASCH, 1953, Vol.I, 266).

Esta forma se documenta también de manera abundante en el Cabezo de Alcalá de Azaila (Teruel), donde su cronología se sitúa ya entre principios del siglo II y principios del siglo I a.C., proponiendo como centro de difusión la Italia Central (BELTRAN LLORIS, 1976, Fig. 51, 850, 852-854, 907, 936 y 999); El Cigarralejo, donde también se fecha a fines del siglo II o comienzos del I a.C. (CUADRADO, 1987, tumbas 145, 190 o 199) o La Albufereta (RUBIO GOMIS, 1986, Fig. 141).

Se trata, pues, de un tipo de vaso que viene recibiendo una cronología bastane baja. Sin embargo, como en el caso de los caliciformes, tal vez su fecha inicial deba ser ligeramente subida $y$, en este sentido, los más antiguos de Almedinilla puedan situarse al menos en la primera mitad del siglo III 
a. C., si bien hemos de reconocer la existencia de variantes en el poblado que pueden se algo más tardías.

TIPO V (Fig. 3)

Conjunto de piezas muy relacionado con los Grupos II y III. En él hemos reunido vasos de mediano tamaño, en todos los casos con decoración pintada, que presentan bordes exvasados redondeados, planos, labiados o en forma de cabeza de ánade-; cuello ligeramente desarrollado, con cierta tendencia acampanada; galbos de perfil globular, a veces con hombros marcados y/o tendencias bitroncocónica e incluso tritroncocónicas, y bases con ónfalo bien indicado y sólo en ocasiones pie apenas insinuado. Sin que en ningún caso muestren una similitud formal absoluta, podemos dividir el Tipo en tres Variantes principales:

Variante A: Bordes labiados, generalmente en forma de cabeza de ave, exvasados y en alguno casi horizontales; cuello estrangulado, con cierta tendencia acampanada; galbos globulares o de perfil biy tritroncocónico y base con ónfalo.

-Variante A/1: Galbo de tendencia globular, al que se pasa desde el cuello sin solución de continuidad. Motivos decorativos integrados en la Subvariante b) (C-181).

-Variante A/2: Galbo de tendencia tritroncocónica. Decoración pintada más compleja, que responde a la Subvariante d) (C-131, y 173 y 178).

Variante B: Bordes planos, a veces ligeramente engrosados, siempre salientes; cuellos apenas indicados, con cierta tendencia acampanada; galbos globulares, en ocasiones de perfil casi bitroncocónico o con hombro marcado mediante un baquetón; bases con ónfalos desarrollados.

-Variante $\mathrm{B} / 1$ : Borde plano, cuello estrangulado, galbo de perfil más o menos globular, ligeramente bitroncocónico, y base con ónfalo. Motivos decorativos complejos, integrables en la Subvariante d) (C-204).

-Variante $\mathrm{B} / 2$ : Borde plano engrosado; cuello estrangulado, perfectamente diferenciado de aquél y del galbo, al que da paso mediante un hombro marcado con un baquetón; base con ónfalo. Motivos decorativos muy complejos, que responden también a la Subvariante d) (C-213).

Variante C: Bordes labiados, salientes; cuellos bastante estrechos en relación al diámetro del gal- bo y con cierta tendencia acampanada. Perfil globular o claramente bitroncocónico, en ocasiones de diámetro superior a la altura total del vaso; bases con ónfalos muy desarrollados.

-Variante C/1: Galbo de tendencia globular simple. Motivos decorativos que responden a la Subvariante c) (C-179).

- Variante C/2: Galbo acusadamente bitroncocónico, de diámetro superior a la altura del vaso, y base con alto ónfalo y pie sugerido. Su categoría cromática responde a la Subvariante b) (C-187).

En total, se conservan 8 ejemplares, que suponen un $4^{\prime} 93 \%$ del total. Aparecen decorados en el $100 \%$ de los casos.

Este grupo de piezas, por lo general con decoraciones muy ricas, de una gran calidad y muy uniformes en cuanto a su factura, son muy características de Almedinilla, destacando por ejemplo nuestra Variante $\mathrm{B} / 2$, sin duda alguna fabricada en el mismo taller de la Variante A/ 1 , Subvariante d, del grupo que describiremos a continuación.

Formas similares a las que integramos como Variante A se observan, por ejemplo, en la Necrópolis de Los Torviscales (VAQUERIZO, 1986, Fig. 1,4); La Guardia (BLANCO, 1959, 89 ss; Tumba 1); El Tesorico (BRONCANO, MARTIN, NEGRETE, PUCH, 1985, 77-78, Figs. 22 y 23); o Toya (PEREIRA, 1979, 333, Tipo 7-D; Fig. 10,3,5-7 y Fig. 11). Son clasificados por C. Aranegui y E. Pla como Forma G-a, integrándose en el primer Estilo Geométrico Simple, que es propio de los yacimientos ibéricos centrados en el s. IV a.C., (ARANEGUI, PLA, 1981, 76, Fig. 6aB).

Por su parte, nuestra Variante $B$ puede identificarse con la Forma 19 que A. Cuadrado establece entre la cerámica de barniz rojo (CUADRADO, 1969, Fig. 10-19) y encuentra paralelos formales en las necrópolis de La Bobadilla (MALUQUER, PICAZO, RINCON, 1973; Tipo V-b; Fig. 21, b) o Toya (PEREIRA, 1979, 333, Tipo 7-C; Fig. 9,10 y Fig. $10,1)$.

Finalmente, la Variante $\mathrm{C}$ aparece constatada, por ejemplo, en las necrópolis de Los Torviscales (VAQUERIZO, 1986, Fig. 1,5); Tutugi (CUADRADO DE ISASA, 1970, 474, Forma 25, Fig. 11,1, Lám. 2). o toya (PEREIRA, 1979, 314 y 330; Tipo 7-A; fig. IX,1 y Lám. V,4).

En conjunto, se trata de un grupo de formas cuya cronología puede remontarse hasta finales del s. V, pero que, sobre todo, aparecen documentadas durante el s. IV. 


\section{TIPO VI}

Incluye piezas de bordes exvasados, vueltos y a veces horizontales, habitualmente planos o redondeados, pero también en forma de cabeza de ánade, apuntados o casi verticales; cuello inexistente o estrangulado, caso en el que aparece separado del galbo por un hombro suavemente marcado; galbo de tendencia panzuda, más o menos acampanada; base con ónfalo y pie indicado, que en la variante B se muestra muy desarrollado. Aparecen con decoración pintada en todos los casos, respondiendo a todas las subvariantes establecidas (Subvariante c): C-215; Subvariante d): C-167; Subvariante e): C-216).

Se conservan 6 ejemplares, que suponen un $3,70 \%$ del total.

Básicamente, podemos distinguir dos Variantes:

\section{Variante A:}

Borde exvasado, vuelto o casi horizontal, y en ocasiones apuntado o en forma de cabeza de ánade; cuello estrangulado, diferenciado del galbo por un hombro más o menos marcado; perfil de tendencia panzuda, siempre más ancho a la altura de los hombros; base con pie indicado y en todos los vasos ónfalo más o menos marcado. Ofrecen siempre decoración pintada, respondiendo a todas las categorías establecidas como subvariantes.

-Variante A/1: Galbo de tendencia panzuda simple (C-168).

- Variante A/2: Galbo con hombro marcado y de perfil más acusadamente acampanado. Sólo aparece un ejemplar de este tipo, cubierto en toda su superficie exterior de barniz rojo (C-214).

\section{Variante B:}

Borde labiado y vuelto, casi en visera; ausencia de cuello; galbo de tendencia acampanada, con un primer cuerpo cilíndrico que, mediante una leve inflexión, da paso a un segundo de tendencia troncocónica, con el vértice hacia la base. Pie alto y complejo, muy desarrollado y añadido con posterioridad a la fabricación de la pieza. Decoración polícroma, que responde a la Subvariante d).

Se trata, en definitiva, de la imitación indígena de una crátera de campana (C-146).

Las piezas que integramos en nuestra Variante A están empezando a ser denominadas de manera genérica con el apelativo de «crateriformes» $y$, según algunos autores, responderían en síntesis a una imitación muy evolucionada de la crátera griega de
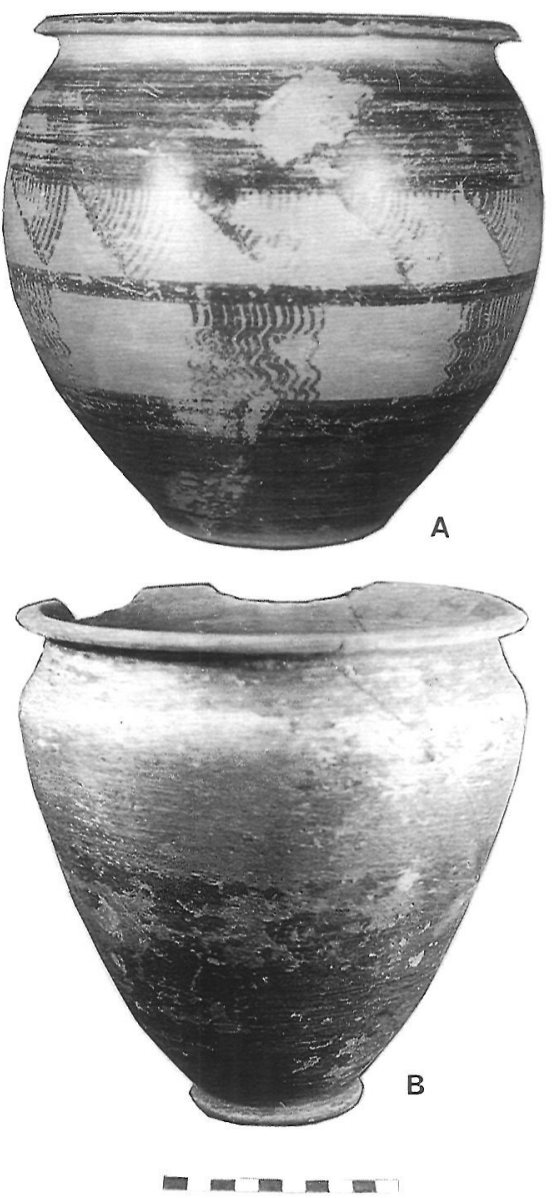

Lám. II:

A) GRUPO 1/TIPO VI/VARIANTE A/1/Subvariante d).

B) GRUPO 1/TIPO VI/VARIANTE A/2.

campana, de la que tan sólo perviviría el perfil, muy esquematizado, desapareciendo las asas (GRIÑO, OLMOS, SANCHEZ, 1984, 284 ss).

Se corresponden con la Forma 21 de E. Cuadrado (CUADRADO, 1969, 268, Fig. 10,21), fechable a finales del s. V o a principios del s. VI, y se constata de manera absolutamente predominante en las necrópolis ibéricas de la Alta Andalucía, caso de Los Torviscales (MARCOS, VICENT, 1983, T. 5, Fig. 8; VAQUERIZO, 1986, Fig. 1,2); Baza (PRESEDO, 1982, tumbas 14, 16, 19, 20, 23, 64, 163 ó 165); La Bobadilla (MALUQUER, PICAZO, RINCON, 1973, Tipo IX, Fig. 26); Castellanos del Ceal (BLANCO, 1963, 87 ss; Fig. 7) o Toya (PEREIRA, 1979, 330, Variante 6-B, Fig. 8,5 y 8,9).

En lo que respecta a nuestra Variante $B$, las imitaciones indígenas de cráteras griegas han sido ob- 
jeto de un reciente trabajo, aún no publicado en el momento en que fue utilizado por nosotros (PEREIRA, SANCHEZ, 1983) (17), en el que se indica que su marco cronológico ha de fijarse entre fines del siglo V y mediados del IV a.C. Para estos autores, el proceso de imitación de las cráteras áticas se inició con la llegada de éstas a Andalucía en el último tercio del siglo $\mathrm{V}$, de forma que las imitaciones más antiguas serían aquellas que reproducen más exactamente los elementos morfológicos y el sistema de proporciones ático. Tras la difusión de este tipo, que pudo realizarse desde Toya, irrumpen en Andalucía a mediados del siglo IV las cráteras de campana, que, a su vez, provocan nuevas imitaciones. Sin embargo, la razón de su escasa representación en las necrópolis andaluzas se explicaría porque habrían sido objeto de una mayor asimilación por parte del indígena, quien no tardaría en integrarlas en los patrones morfológicos y decorativos de su propia cerámica, surgiendo así los crateriformes.

De acuerdo, pues, con estos autores, que relacionan además la aparición de este tipo de imitaciones con la ruta comercial del Guadiana Menor, las piezas que constituyen nuestra Variante A serían posteriores a las imitaciones más fidedignas del prototipo griego, caso de nuestra Variante B. Por tanto, su cronología debería ser fijada con posterioridad al 350 ac.C., lo que, de ser así, invalidaría datas mucho más antiguas aplicadas en yacimientos próximos al que nos ocupa (18).

Por otra parte, no cabe duda de que este tipo de piezas son una prueba fehaciente de la asimilación de impulsos griegos llegados hasta estas tierras (OLMOS, 1982; ALMAGRO GORBEA, 1982).

\section{TIPO VII (Fig. 4)}

Grupo de piezas de gran tamaño, muy relacionadas con el Tipo I, pero con las características di-

(17) Queremos, desde aquí, expresar nuestro agradecimiento a los autores, quienes no mostraron inconveniente alguno en cedernos una copia del original ni en que sus conclusiones fueran utilizadas para nuestro estudio.

(18) En concreto, nos referimos a la necrópolis de la Bobadilla (MALUQUER, PICAZO, RINCON, 1973), que desde un primer momento se fechó en función de la Cámara A entre mediados del siglo VI y mediados del siglo V a.C. A nuestro juicio, esta cronología resulta excesivamente alta en lo que a su límite inferior se refiere $y$, sin duda, debe hacerse llegar hasta el siglo IV, al menos a su primera mitad. ferenciales de su gran altura respecto al diámetro máximo del galbo; su tendencia ligeramente bitroncocónica, y sus bordes labiados, vueltos y casi horizontales, ofreciendo un aspecto muy particular. Presentan además cuellos estrangulados y casi inexistentes y bases con alto ónfalo, sin pie. En los casos conocidos muestran en su superficie exterior las líneas del torno muy marcadas, formando auténticas acanaladuras que son utilizadas como efecto decorativo. Ofrecen una gran similitud formal con la imitación de un ánfora de orejetas que clasificamos como Tipo X - su perfil resulta idéntico, a excepción del remate de la base- $\mathrm{y}$ en ningún caso llevan decoración pintada (Números C-151, 180 y 211).

Con 3 ejemplares, representan un $1,85 \%$ del total.

Se trata de piezas que pueden ser relacionadas con las ya mencionadas «jarras bitroncocónicas de origen languedociense», en función de cuya clasificación podrian fecharse entre fines del siglo VI y principios del III, y que en las necrópolis del foco andaluz se constatan por ejemplo en Baza, donde aparecen individualizadas como Variante e). La cronología general de esta necrópolis se sitúa a partir de principios del siglo IV a.C. (PRESEDO, 1982, Tumba 59, Fig. 69,2).

\section{TIPO VIII (Fig. 4)}

Incluye una serie de piezas de muy pequeño tamaño, que vienen a ser como una versión reducida de formas ya estudiadas en tipos anteriores (especialmente en el I), y que debieron servir para contener perfumes, ungüentos o cualquier otra materia más o menos preciosa, digna de ser incorporada al ajuar del difunto. Hallamos vasos cerrados, con bordes exvasados, labiados o redondeados; cuello estrangulado o ligeramente indicado; galbos de perfil más o menos globular, casi siempre de acusada tendencia bitroncocónica, y base con ónfalo, a veces muy marcado.

Se conservan 3 ejemplares, que representan el $1,85 \%$ del total.

Podemos señalar 2 variantes:

Variante A:

Borde labiado, saliente; cuello estrangulado, casi inexistente; galbo con fuerte tendencia bitroncocónica, reflejada mediante una acusada carena que separa de la parte superior de la pieza su tercio 

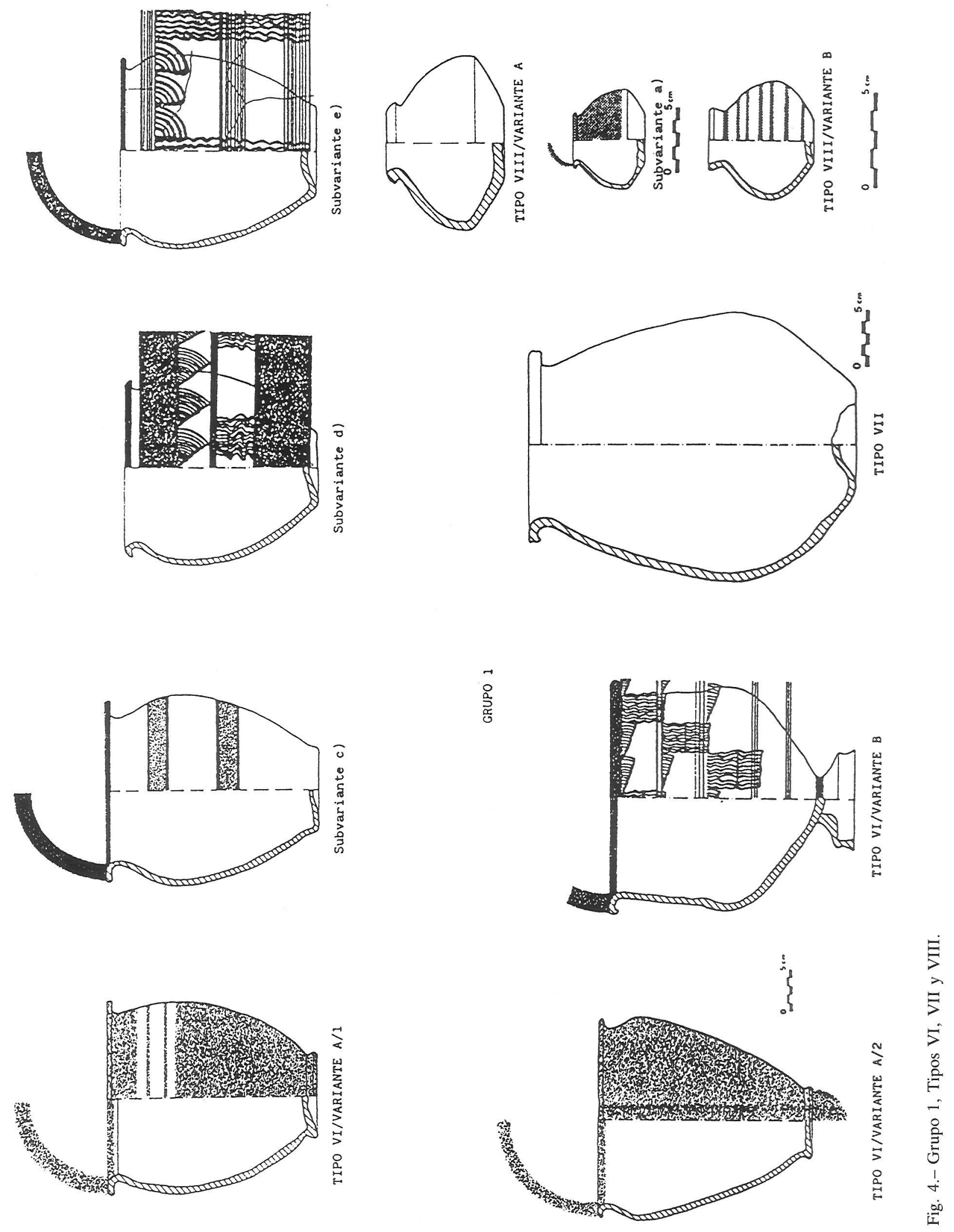
inferior, que adopta un perfil casi cóncavo, y base prácticamente plana (MAN. Número 85/56/14).

Cuando aparecen con decoración, ésta suele cubrir la parte superior del vaso o bien toda su superficie, respondiendo, pues, a la Subvariante a). Aunque en el poblado resulta una forma bastante frecuente, entre el material antiguo sólo se conserva un ejemplar (Número C-295).

\section{Variante B:}

Borde exvasado, redondeado; cuello estrangulado, apenas indicado; galbo de perfil globular con cierta tendencia bitroncocónica y base con ónfalo. Presenta un sólo ejemplar, que aparece decorado en toda su superficie exterior mediante un sistema de estrechas bandas horizontales realizadas con pintura monócroma (MAN. Número 85/56/5).

En lo que respecta a la Variante $A$, en un principio fue catalogada por E. Cuadrado entre la cerámica de barniz rojo como Tipo $\mathrm{D} 3$, asignándole una cronología entre fines del siglo $\mathrm{V}$ y comienzos del siglo III a.C., con su apogeo en el siglo IV (CUADRADO, 1953, 278, Fig. 4,4). Más tarde, sería reclasificada como Forma $4 \mathrm{~b}$, sin modificar su cronología (CUADRADO, 1966, 38-39). Constituye un modelo cerámico muy difundido por toda el área ibérica.

En cuanto al vaso que caracteriza nuestra Variante $\mathrm{B}$, no le hemos hallado paralelos exactos en los yacimientos consultados, pero formas similares - aunque con pie marcado en todos los casos-son catalogadas por E. Cuadrado entre las botellitas que designa como Forma 21. Así, una pieza con decoración a bandas polícromas, cuya morfología recuerda a la que nos ocupa, se constata en la tumba 153 , de El Cigarralejo, fechada entre el 375 y el 350 a.C. (CUADRADO, 1987, Fig. 128, 5 y 6).

En definitiva, nos hallamos ante un tipo de vasos cuya aparición pudo tener lugar a fines del siglo V. a.C. o principios del IV y que, normalmente, aparece asociado a contextos materiales del siglo IV, si bien sigue constatándose durante todo el siglo III e incluso principios del siglo II a.C. (GARCIA, INIESTA, 1983, 566 ss).

\section{TIPO IX (Fig. 5)}

Aparece integrado por una sola pieza, repetidamente reproducida como una de las más originales entre las recuperadas en la necrópolis de Los Collados. Presenta un borde moldurado, engrosado y entrante, galbo globular de tendencia casi esférica y base con pie indicado y ónfalo. El hombro, inexistente, parece sustituido por una línea de estampillados en forma radiada. Además de este elemento, presenta como decoración una densa capa de barniz rojo vinoso que cubre el interior del labio y toda la superficie exterior, a excepción de la zona ocupada por las estampillas, una estrecha banda en reserva y la línea del pie. En la parte superior del galbo ofrece una ancha franja que, hoy, presenta un tono de color diferente, pero que puede deberse a una degeneración del utilizado originalmente (Número C-171). Como ejemplar único, representa el $0,61 \%$ del total.

Este ejemplar concreto ha dado lugar a la Forma 22 de la cerámica de «barniz rojo ibéricotartesio» en la clasificación de E. Cuadrado (CUADRADO, 1969, 268, Fig. 10,22). Sin embargo, no se trata de un modelo de vaso habitual en el mundo ibérico y, de hecho, sus únicos paralelos los hemos constatado siempre en el área celtibérica. Así por ejemplo, piezas similares, tanto en lo que respecta al borde como a la morfología del galbo, decorado en ocasiones con bandas pintadas o molduras que coinciden en su disposición con las dos líneas más estrechas de pintura que marcan el hombro de nuestro tipo, se documentan en varios yacimientos de Navarra, destacando por su extraordinaria similitud un vaso procedente de La Custodia (CASTIELLA RODRIGUEZ, 1977, Fig. 209,5), cuya cronología se puede fijar entre fines del siglo IV y comienzos del siglo III a.C.

Igualmente, bordes de la misma morfología se han hallado en el yacimiento de Oreto (Cerro Domínguez, Granátula de Calatrava, Ciudad Real), donde existe algún caso que presenta un galbo de tendencia similar y decoración pintada, pudiéndose fechar en el siglo IV a.C. (NIETO, SANCHEZ, POYATO, 1980, Fig. 30, 39).

En lo que respecta a su decoración estampillada, su tipo de estampilla se incluiría en el Grupo B1 de Ruiz y Nocete: enmarques ovalados ocupados por un motivo en eje, que ofrece ejemplos similares en Santisteban del Puerto, Martos, Castellar de Santisteban, Castulo o Puente Tablas (RUIZ, NOCETE, 1981, 356, 357; Figs. 3, 20, 22, 23, 25 y 26, respectivamente). Para estos autores la decoración con estampilla en el Alto Guadalquivir está ausente de lo que podemos considerar vajilla de uso ordinario y constituye un elemento decorativo muy apreciado. 

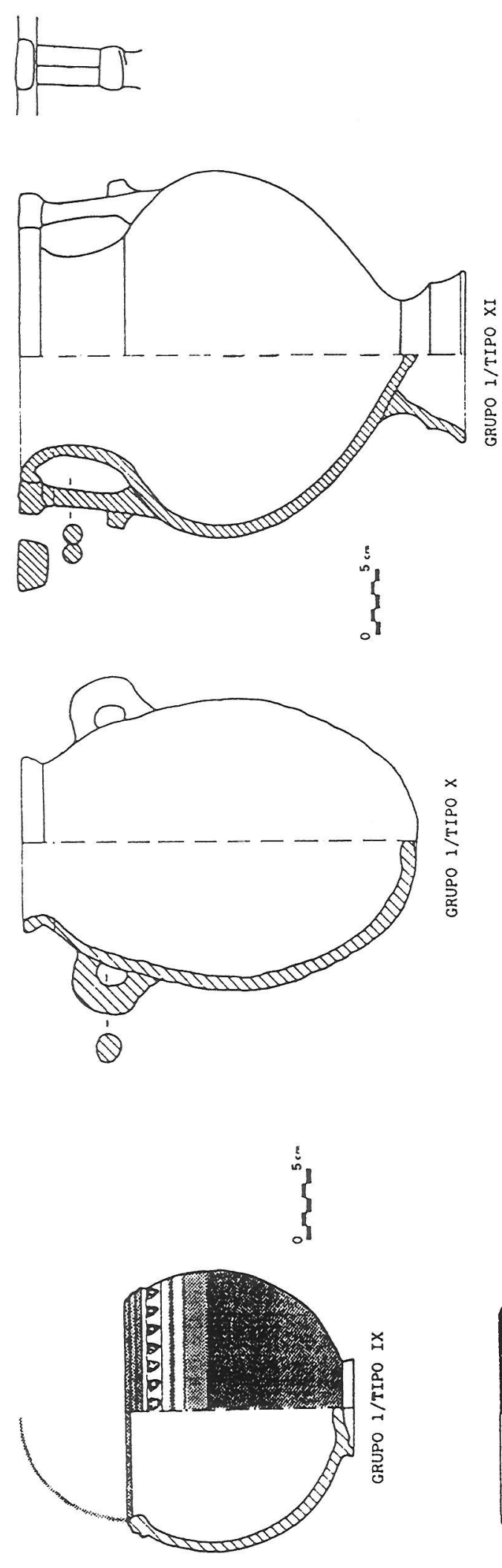

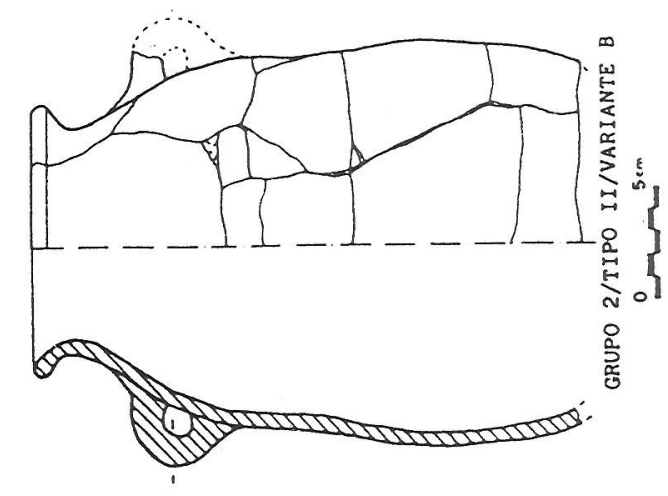

Q

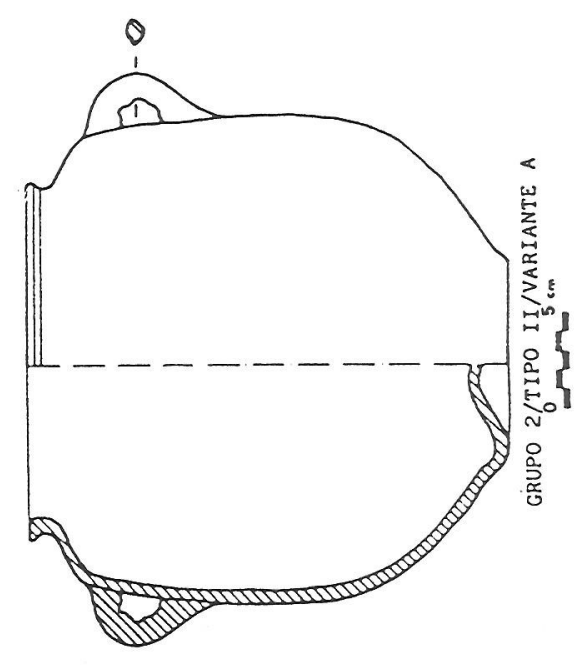

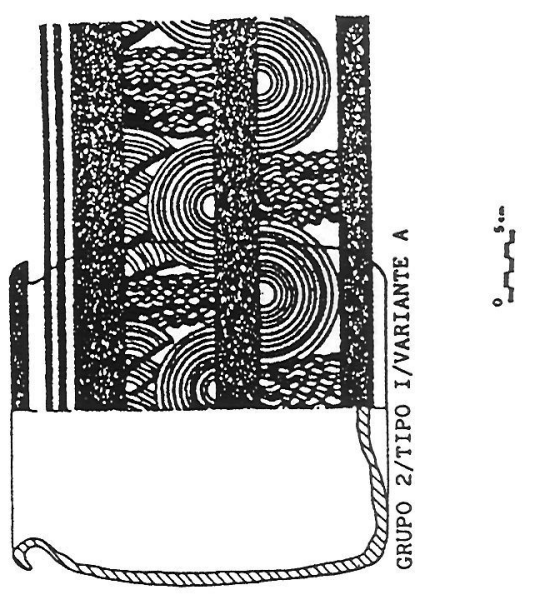

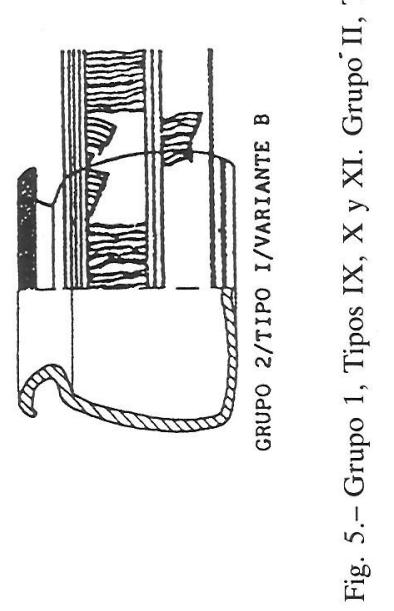


TIPO X (Fig. 5)

Imitación indígena de ánfora púnica. Borde plano, levemente labiado al exterior y exvasado; cuello estrangulado, casi inexistente; galbo con el hombro apenas marcado, del que parten dos grandes asas del tipo que conocemos como «orejetas», de sección anular; altura muy superior al diámetro máximo y base convexa, sin pivote y con ligero umbo interior. Ambas superficies con líneas de torno muy marcadas, formando acanaladuras que en la exterior se utilizan en cierto modo como efecto decorativo. El único ejemplar que se conserva entre el material antiguo no presenta decoración pintada (número C-165). Supone el 0'61\% del total.

El ánfora suele ser un elemento muy abundante en los yacimientos ibéricos, si bien hasta hace pocos años ha sido muy poco valorado. Ultimamente está siendo objeto de abundantes trabajos e intentos de sistematización (PELLICER, 1978, 365 ss; RIBERA LACOMBA, 1982; PELLICER, ESCACENA, BENDALA, 1983; FLORIDO NAVARRO, 1984 y 1985) y, poco a poco, se está convirtiendo en un importante fósil director que, en ocasiones, puede servir para fechar determinados contextos arqueológicos. No bstante, al tratarse por lo general de imitaciones locales, sus variantes son múltiples y aún queda mucho camino por recorrer.

Existen casos que demuestran su documentación también en contextos funerarios y, en concreto, además de en Los Collados, conocemos ejemplares similares en las necrópolis de Los Torviscales (19) y en la de Baza (20). En ambos yacimientos, su cronología se puede fijar en la primera mitad del siglo IV a.C.

(19) Una pieza absolutamente idéntica a la que determina nuestro tipo se constata en la tumba 9, fechada por la aparición en ella de un kylix-skyphos de barniz negro ático atribuible a la primera mitad del siglo IV a.C. (MARCOS, VICENT, 1983).

Otro ejemplar de las mismas características se conserva en la Colección Arqueológica del Ayuntamiento de Fuente Tójar, que permanece inédita.

(20) PRESEDO, 1982, 296, Fig. 172.

Cuatro ánforas similares a la que nos ocupa, con decoración pintada muy peculiar, fueron recuperadas en la famosa tumba 155, junto a la Dama de Baza, tratándose sin lugar a dudas, según su excavador, de piezas de fabricación indígena. Su cronología se fija en la primera mitad del siglo IV a.C.
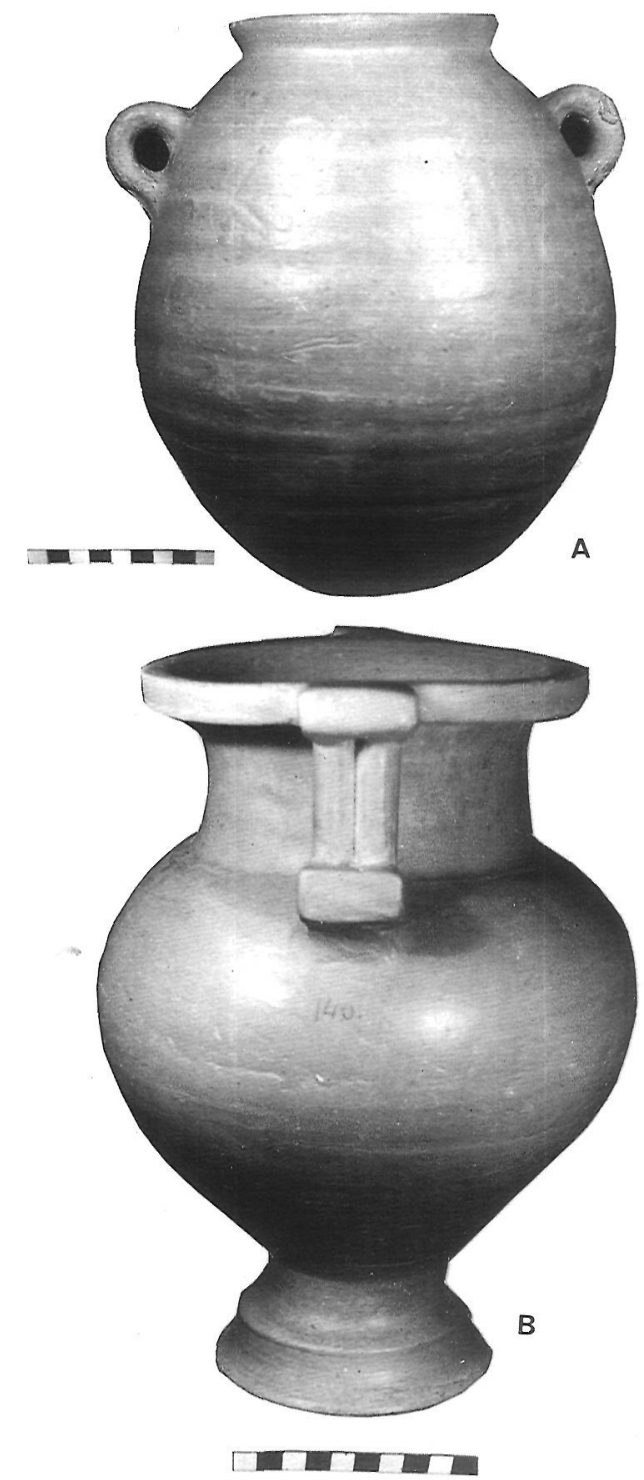

Lám. III:

A) GRUPO 1/TIPO X. B) GRUPO 1/TIPO XI.

\section{TIPO XI (Fig. 5)}

Imitación indígena de crátera de columnas griegas. Borde labiado en forma de pico de ave, exvasado; cuello desarrollado, de tendencia acampanada; galbo de perfil globular, casi esférico, con un hombro suavemente marcado en el que se apoyan la asas, formadas por dos columnas de sección anular con sendos refuerzos de morfología rectangular en su unión con el borde y en la pared inferior; base de tipo convexo, apuntada, a la que se añadió con posterioridad un alto pie moldurado de gran per- 

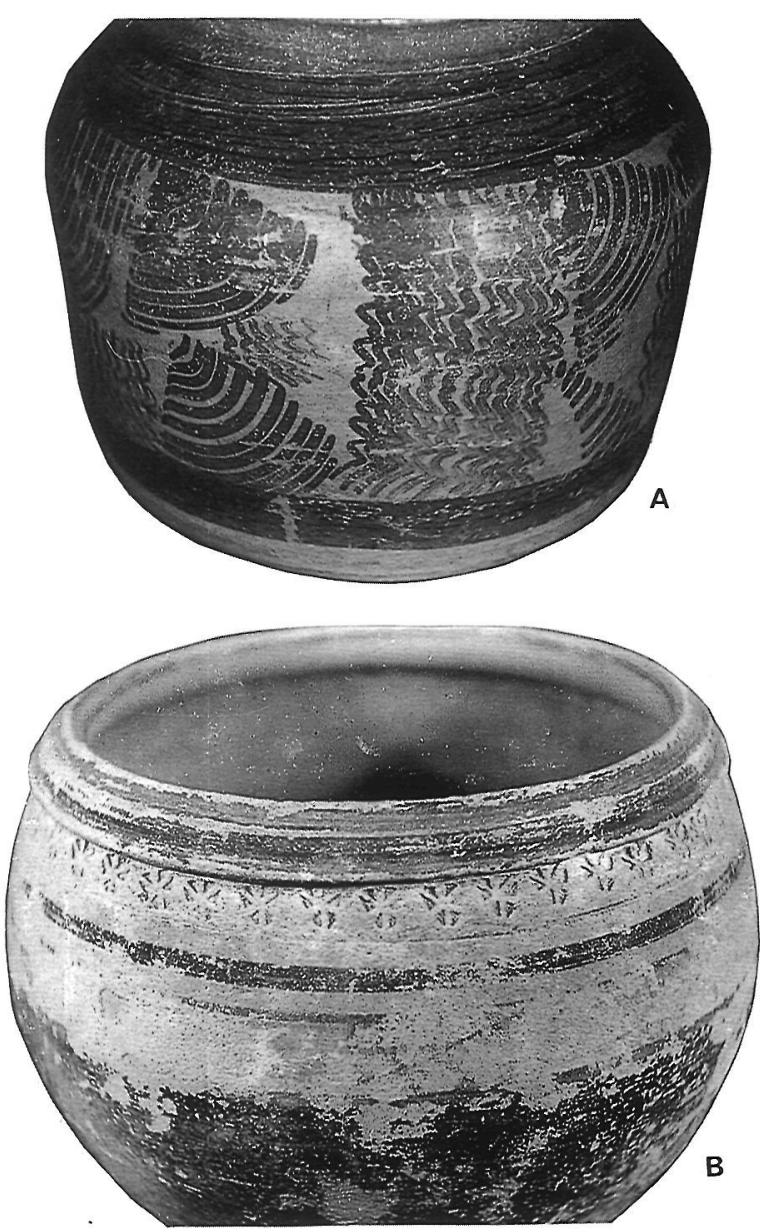

Lám. IV:

A) GRUPO 2/TIPO I/VARIANTE A/Subvariante d).

B) GRUPO 1/TIPO IX.

fección y elegancia. En el caso que se nos ha conservado completa (número C-140), la pieza no presenta decoración alguna (aunque tal vez fue borrada por el salvaje lavado a que se la sometió), pero un pie registrado independientemente (número C191), y que puede relacionarse también con el Tipo, sí ofrece decoración pintada a bandas en su anillo de apoyo y en la moldura exterior.

Si esta segunda pieza puede identificarse, en efecto, con el pie de una crátera, este tipo representaría el $1,23 \%$ del total.

En contextos funerarios, las imitaciones de cráteras de columnas pudieron ser utilizadas, en idéntico sentido que las cajas cineraria o larnakes, como una reproducción simbólica de la casa; incluso, se ha llegado a plantear el que fueran vasos concebidos fundamentalmente como recipientes funera- rios (OLMOS ROMERA, 1982, 263-264). En cualquier caso, entroncarían en la corriente de formación y plenitud del mundo ibérico, que acepta aún con enorme afán sincrético elementos culturales foráneos, reinterpretándolos e integrándolos en su cultura hasta el punto de que pudieran tomar distinto significado.

El mapa de dispersión de este tipo de piezas en Andalucía indica su existencia en Villaricos (ASTRUC, 1951, 55); Galera (CABRE, MOTOS, 1920, 29); Baza (PRESEDO, 1982, tumbas 27, 43, 83-A, 98, 118, 125 y 130); Cortijo Colorado (Gor, Granada) (PEREIRA, SANCHEZ, 1983, Fig. I, número 5); Toya (PEREIRA, 1979, 318, Tipo 9-a, Fig. XIV, 1 y 2; Lám. VII, número 4) a Bobadilla (MALUQUER, PICAZO, RINCON, 1973, Fig. 11, número 11) y Los Torviscales (inédita).

Por otra parte, su difusión en el Levante ha sido analizada por V. del Page, para quien las imitaciones de las Bastetania y del Sureste presentan diferencias bien marcadas, observándose por lo general una cronología más tardía para las levantinas: si bien las más antiguas pueden remontarse al último tercio del siglo $\mathrm{V}$ a.C., las más modernas abarcan hasta mediados del siglo III (PAGE, 1984, 62 ss).

En conclusión, la cronología de estas piezas debe fijarse entre fines del s. V y la segunda mitad del s. IV a.C.

\section{GRUPO 2}

\section{TIPO I (Fig. 5)}

Conjunto de piezas de bordes exvasados, labiados en todas las ocasiones y a veces casi horizontales; cuello estrangulado, que se separa del galbo a través de un hombro más o menos marcado; galbo cilíndrico, normalmente con cierta tendencia al abombamiento, y bases planas, siempre con ónfalo indicado, y en alguna ocasión también con umbo interior.

Son las formas que designamos habitualmente como kalathoi, portadoras en todos los casos de una decoración abigarrada que llega a poner en evidencia cierto horror vacui y que responden siempre a la categoría cromática clasificada como Subvariante d). Se conservan seis ejemplares, de los cuales uno presenta identidad absoluta en cuanto a motivos decorativos y barniz utilizados con la pieza que determina nuestro Tipo $\mathrm{V} /$ Variante $\mathrm{B} / 2$, pudiendo afir- 
mar sin temor a equivocarnos que se trata de un mismo taller.

Con 6 ejemplares, este tipo representa el 3,7\% del total de piezas.

Distinguimos dos Variantes:

\section{Variante A:}

Características globales similares a las ya descritas. Borde labiados, a veces en visera, hombro escasamente pronunciado y tamaño bastante grande, superando por lo común su altura al diảmetro máximo del galbo (Números C-136, 137 y 837).

Aparece decorada en todos los casos, mezclando motivos geométricos en todo tipo de combinaciones, siempre dentro de la categoría monócroma.

\section{Variante B:}

Características generales semejantes. Bordes comunmente en forma de cabeza de ánade; cuello muy estrangulado, marcando con claridad la transición al galbo mediante un hombro angulado; galbos de sección cilíndrica o con cierta tendencia abombada y altura por lo general inferior al diámetro máximo de la pieza (Números C-135, 139 y 185).

Presentan también una gran riqueza decorativa, siempre dentro de la Subvariante d), empleando motivos, como series de puntos dispuestos en líneas paralelas oblícuas, que no son habituales en el yacimiento.

Se trata del tipo cerámico que presenta un mayor barroquismo decorativo entre todas las piezas conservadas de la necrópolis; ello debe ser interpretado como un símbolo de prestigio $\mathrm{y}$, a la vez, nos da una idea de la alta estimación comercial de la pie$\mathrm{za}$, elemento suntuario no accesible posiblemente a cualquier bolsillo.

Aunque en su origen deba relacionarse con el mundo clásico, la forma que estamos analizando puede considerarse como una de las creaciones ibéricas más antiguas, no constatadas en los repertorios ibéricos de primera época. Cronológicamente, surgió primero el modelo de cuello estrangulado y, años más tarde, a partir del siglo III a.C., este primer tipo se vería sustituido por la generalización del recipiente cilíndrico con bordes en visera que conocemos vulgarmente com "sombrero de copa» y que resulta característico, sobre todo, de la zona levantina, donde sirve a veces de base a algunas de las composiciones pictóricas más logradas de la cultura ibérica.

En el País Valenciano la fecha de aparición del kalathos de cuello estrangulado se puede fijar en el siglo IV, más o menos en su segunda mitad (ARANEGUI, PLA, 1981, 77-78). En Andalucía el tipo básico, conteniendo ya sus más característicos elementos morfológicos, se constata por primera vez en el Nivel 14 del Cerro Macareno, aún dentro de la fase del Ibérico Inicial, con una cronología de la segunda mitad del siglo $\mathrm{V}$ a.C. (PELLICER, ESCACENA, BENDALA, 1983, 95, Figs. 46,1328 y 104,9). Resulta especialmente similar a nuestra Variante $\mathrm{A}$.

\section{TIPO II (Figs. 5 y 6)}

Conjunto de vasos muy relacionables con el tipo anterior, sobre todo en lo que respecta a su Variante $A$, si bien ofrece diferencias sustanciales que obligan a considerarlo de manera diferenciada. Muestran bordes redondeados o labiados, salientes en dos de los tres vasos; cuello estrangulado y casi inexistente, que da paso al galbo a través de un hombro más o menos carenado del que arrancan dos asas, casi siempre de sección anular; galbo de perfil predominantemente cilíndrico, con tendencia tritroncocónica en dos casos, y base con pie insinuado o indicado y ónfalo.

Aparecen siempre sin ningún elemento decorativo y representan, con 3 ejemplares, el $1,85 \%$ del total.

Distinguimos tres Variantes:

Variante A (fig. 5)

Borde labiado, engrosado y ligeramente entrante; cuello estrangulado, diferenciado del galbo mediante un hombro carenado del que arrancan dos asas de tipo orejeta y sección anular; perfil cilíndrico en el cuerpo central y troncocónico en el inferior, al que se une mediante una ligera carena, tomando en conjunto aspecto tritroncocónico; base con ónfalo y pie apenas indicado. Gran tamaño y ausencia de decoración (Número C-180).

\section{Variante B (fig. 5)}

Borde redondeado y exvasado; cuello estrangulado y casi inexistente, que introduce el galbo a través de un hombro suavemente carenado sobre el que apoyan dos asas de tipo orejeta y sección anular; galbo con tendencia cilíndrica, de mayor anchura en su parte inferior, que parece iniciar una leve carena para dar paso a la base o a un tercer cuerpo troncocónico; base perdida. No decorado (Número C-166). 


\section{Variante C (Fig. 6)}

Borde redondeado y apenas saliente; cuello prácticamente inexistente; galbo de tendencia tritroncocónica, con un cuerpo central de perfil más o menos cilíndrico y dos más troncocónicos, el superior muy corto y el inferior mucho más desarrollado y casi cóncavo. Sobre el núcleo central apoyan dos amplias asas de sección en forma de cinta. La base aparece con pie indicado y ónfalo relativamente alto. La pieza que determina el tipo no presenta decoración y, además, muestra un lamentable estado de conservación (MAN. Número 12.648).

En conjunto, los vasos que constituyen nuestro Tipo II pueden relacionarse con las que J.J. Jully denomina «jarras tritroncocónicas de tipo púnico», que, según él, se pueden considerar una evolución de la jarra «à épaulement» del tipo Cintas BIIb3 (CINTAS, 1970, 353 ss; Láms. XXXIII y XXXIV), si bien ésta presenta generalmente el cuerpo ovoide o en fondo de saco. Como base para su cronología se indica una pieza procedente de Castellones de Ceal, fechable entre el 600 y el 425 a.C. (JULLY, 1975, 47-48, Fig. 32).

Esta forma ha sido sistematizada en la necrópolis de El Cigarralejo, donde el vaso que caracteriza nuestra Variante A puede relacionarse desde el punto de vista morfológico con los Tipos $1 \mathrm{~b}$ y $2 \mathrm{~d} 2$, que, según su excavador, debieron servir para cereales o líquidos, como vino y aceite, en gran cantidad (CUADRADO, 1972, 126, Tabla I; 127, Tabla III). Al mismo tiempo, podemos identificarla con la que C. Aranegui y E. Pla denominan Forma 25: «Urnas tritroncocónicas con tapaderas» (ARANEGUI, PLA, 1981 ss), y señalar la aparición de ejemplares similares en Toya (PEREIRA, 1979, Grupo 11, Fig. 15,6); Los Torviscales (VAQUERIZO, 1986, Fig. 1,3) o Los Villares (Caudete de las Fuentes, Valencia) (PLA, BALLESTER, 1980, 51, Departamento 11, Estrato 11, Lám. XIII,1). En conjunto, su cronología se puede precisar entre mediados del siglo IV y mediados del siglo III a.C.

La Variante B, que presenta un paralelo casi idéntico en la necrópolis de Los Torviscales - cuya cronología se fija, como sabemos, entre mediados del siglo VI y mediados del siglo IV a.C. (MARCOS, VICENT, 1983, Fig. 8,1)- debe relacionarse, a nuestro juicio, con la variante anterior, constituyendo posiblemente una degeneración local del mismo modelo.

Por fin, en lo que respecta a nuestra Variante $\mathrm{C}$, podemos señalar un paralelo casi idéntico en el yacimiento de El Amarejo (Bonete, Albacete). Fue recuperado en el Estrato 2 del Departamento 4 y presenta decoración pintada de motivos geométricos. No se indica claramente su cronología, pero la vida del poblado se fija al menos entre el siglo IV y comienzos del siglo II a.C. (BRONCANO, BLANQUEZ, 1985, Fig. 93,110).

\section{TIPO III (Fig. 6)}

Vasos de borde ligeramente entrante y galbo de tendencia cilíndrica, algo abombado, que adopta un perfil troncocónico en su tercio inferior, dando así paso a la base, con pie indicado y ónfalo. En el caso conservado entre el material antiguo, el borde aparece labiado al interior y en su superficie exterior muestra decoración pintada monócroma dispuesta en bandas concéntricas, por lo que se incluye dentro de la Subvariante b) (Número C-303).

Representa, al ser ejemplar único, el $0,61 \%$ del total.

Parece tratarse de una especie de píxide o tarro que, con toda probabilidad, debió ir cubierto por una tapadera. Resulta similar a la Forma 21 de Aranegui y Pla, que denominan albarello, creación propia de la cerámica ibérica, y puede relacionarse con ejemplares constatados, por ejemplo, en la Bastida de les Alcuses (Mogente, Valencia) (ARANEGUI, PLA, 83-84, Fig. 21); Cortijo de Casas Hurtado (Jaén) (GONZALEZ NAVARRETE, 1967, 30, Lám. X) o con la misma pieza señalada anteriormente como paralelo de nuestro Tipo II/Variante B en la necrópolis de Los Torviscales (MARCOS, VICENT, 1983, Fig. 8,1). En todos los casos produce la impresión de que se trata del mismo tipo pero interrumpido hacia la mitad. Su cronología creemos que no debe subirse más allá de mediados del siglo IV a.C.

\section{GRUPO 3}

Incluimos en él todo tipo de platos, cuencos, páteras y piezas abiertas, habitualmente de pequeño o mediano tamaño y con caracteres morfológicos muy diversos. En realidad, resulta muy difícil distinguir qué tipos fueron concebidos en origen como tapaderas y cuáles serían fabricados con la única misión de contener alimentos, máxime si tene- 


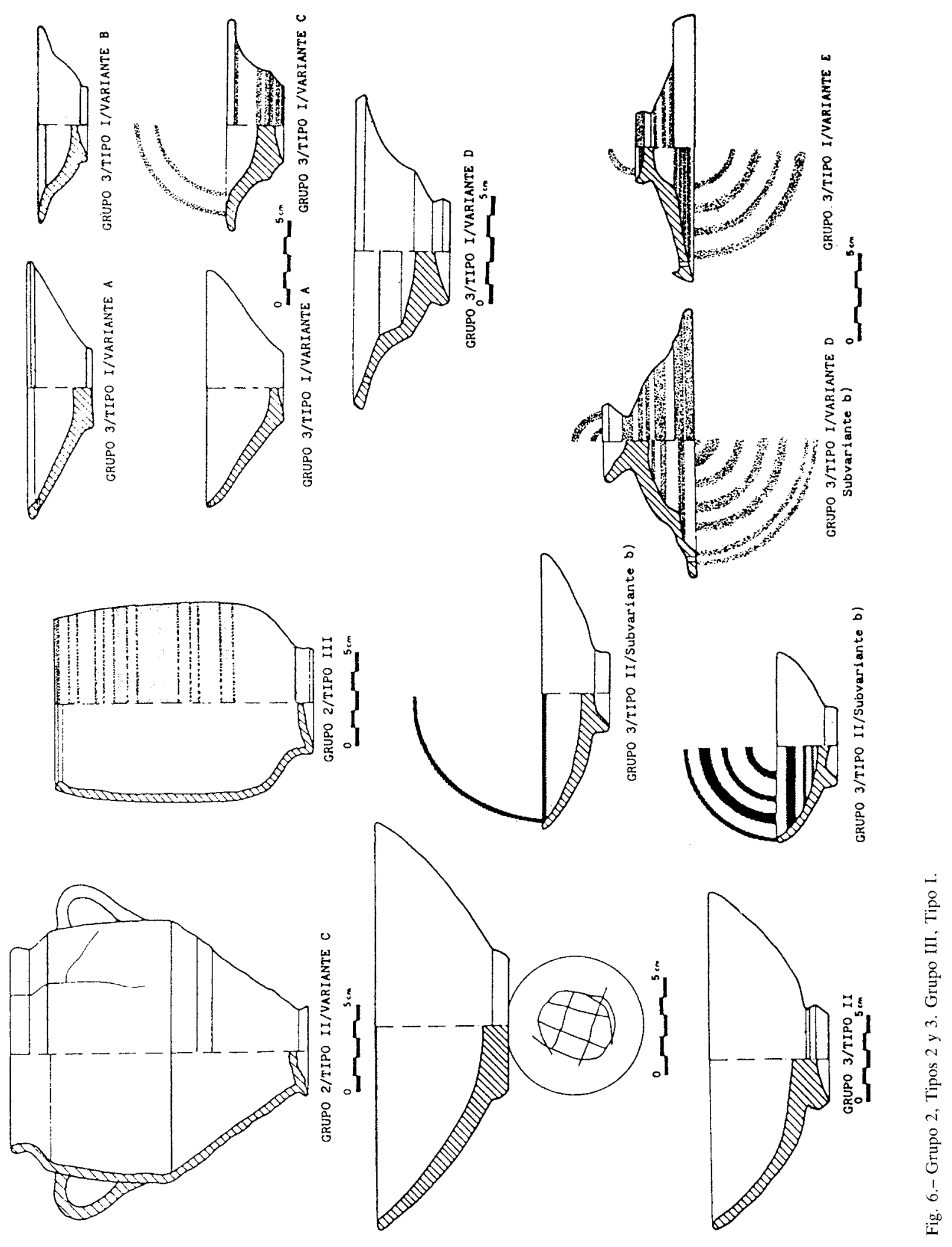


mos en cuenta que muchos de aquéllos serían utilizados como sustitutivos de éstas en los enterramientos. Esto nos obliga a ser bastante circunspectos en la denominación de cada tipo y, lógicamente, añade un elemento de riesgo a nuestra clasificación, por lo demás ajena a todo intento de sistematización cronológica.

En definitiva, se trata del grupo de piezas que con mayor seguridad podemos incluir en el concepto de «vajilla doméstica», que, al parecer, fue tomado del mundo griego y comenzó a extenderse en España entre los siglos V y IV a.C., implicando a la vez el paso del recipiente entendido comunitariamente a la vajilla con valor individual y tal vez una especialización de las formas asociadas a nuevas costumbres culinarias (PAGE DEL POZO, 1984, 182).

\section{TIPO I (Fig. 6)}

Integramos en él aquellas piezas que, formal y funcionalmente, parecen responder con mayor exactitud al prototipo de tapadera, pero sin olvidar que todas ellas han sido interpretadas en otros yacimientos como platos o cuencos y que, en su origen, pudieron ser concebidas como tal. Esto ha determinado que en nuestros dibujos aparezcan representadas como platos, con la base en su apoyo de menor diámetro, salvo en el caso de uno de los ejemplares de la Variante D y en el de la Variante E, cuya funcionalidad específica nos parece fuera de toda duda.

Son formas que representan una gran diversidad, con bordes redondeados, planos o labiados, siempre exvasados y en algunos casos prácticamente horizontales; galbos de tipo convexo, a veces de perfil troncocónico o semiesférico y por lo general con una o varias carenas, y bases con pie más o menos desarrollado y, en el caso de la Variante E, pronunciado umbo interior. Cuando presentan decoración, al menos en el caso de los ejemplares que la han conservado, se trata siempre de bandas concéntricas de distinta anchura, que se disponen en ambas superficies --incluyendo el interior del ónfalo, casos en los que se refuerza nuestra hipótesis acerca de su funcionalidad-- y que responden a la categoría monócroma, por lo que se engloban en la Subvariante $b$ ).

Integramos en este grupo 6 ejemplares, que constituyen el 3,70\% del total. Aparecen decorados, siempre de forma monócroma, en 3 casos.
Distinguimos cinco Variantes:

\section{Variante A:}

Bordes redondeados, a veces labiados por el interior, exvasados o levemente entrantes; galbo de tendencia troncocónica y base casi plana, con pie apenas señalado y ónfalo muy bajo. Los dos ejemplares conservados carecen de decoración y presentan en ambos casos dos orificios de suspensión (Números C-243 y 254).

\section{Variante B:}

Borde apuntado, horizontal y diferenciado del cuerpo mediante una carena interior, galbo convexo y base con ónfalo y pie indicado. No presenta decoración (Número C-249).

\section{Variante $\mathrm{C}$ :}

Borde redondeado y saliente, casi horizontal, que tan sólo se diferencia del galbo mediante una pronunciada carena exterior, a partir de la cual el pie adopta un perfil convexo. Base con ónfalo. Decoración monócroma en ambas superficies, dispuesta en bandas horizontales de diferente grosor (Número C-251).

\section{Variante D:}

Borde plano o redondeado, fuertemente exvasado o en visera; galbo con una o varias carenas, marcadas interior y exteriormente, y base con pie y ónfalo bastante desarrollados. Se conserva un ejemplar no decorado (MAN. Número 12.607) y otro con decoración en ambas superficies basada en líneas concéntricas que ocupan incluso el interior del ónfalo (Número C-253). En este último caso no cabe duda de su interpretación como tapadera, hecho confirmado además por el mayor desarrollo del elemento de pretensión.

\section{Variante E:}

Borde labiado al exterior, muy exvasado; galbo casi plano y base con pie bien marcado y profundo umbo interior, que se diferencia del cuerpo mediante una fuerte carena. El ejemplar conservado muestra decoración monócroma de bandas paralelas en ambas superficies, dejando tan sólo en reserva el pocillo interior. Se trata de una imitación de los típicos «platos de pescado», característicos de la época colonial, y su utilización como tapadera nos parece indudable. Presenta dos orificios de suspensión (Número C-296).

A nuestro juicio, los vasos que caracterizan nuestra Variante A, especialmente la de borde labiado al interior, deben relacionarse con prototipos de platos de cerámica gris adscribibles a época orientalizante, de los que constituirían una simple per- 
duración morfológica. Nos obstante, cualquier afirmación tajante en este sentido resultaría arriesgada en exceso, dada nuestra falta casi absoluta de datos y la simplicidad formal de la pieza (21).

Por su parte, los ejemplares que constituyen nuestras Variantes B, C y D, pueden tal vez ser puestos en contacto, al menos en lo que a su morfología se refiere, con las piezas que González Prats cataloga en la Peña Negra como Tipo E2: «platillos de ala ancha», que, a su vez, derivarían de los platos de barniz rojo fenicios y que, según su excavador, constituyen una producción distintiva de Peña Negra II, cuya cronología se centra en los siglos VIIVI a.C. (GONZALEZ PRATS, 1983, 165-166, 212213; Fig. 36,9).

Ahora bien, para situar cronológicamente estas piezas debemos buscar ejemplares semejantes en contextos arqueológicos de época ibérica. Así, para nuestra Variante $\mathrm{B}$ podemos citar los yacimientos de Cerro Macareno (PELLICER, 1982, 400, Niveles $14-12$, n. $^{\circ}$ inv.: 1.308 ; Fig. 21,15 ), donde presenta una cronología entre fines del $\mathrm{s}$. $\mathrm{V}$ y principios del s. IV a.C., y necrópolis de Las Madrigueras (ALMAGRO GORBEA, 1969, 144, Estrato II, Tipo IV, tipo 7, n. ${ }^{\circ} 16$ a 19); para la C, la Serreta de Alcoy (ARANEGUI, 1970, 120-121, Fig. 4,34-3 y 1967) y la necrópolis de La Guardia (BLANCO, 1959, 89 ss; tumba 1), donde se fecha en la primera mitad del siglo IV a.C.; y, por fin, para la D, Alhonoz (LOPEZ PALOMO, 1981, 62 ss; Forma 2, Estratos III y II de 1977, Fig. 18) y el Amarejo (BRONCANO, BLANQUEZ, 198543 ss; Dpto. I, Estrato 2 , n. ${ }^{\circ} 42$, Fig. 11,42 ), con una cronología que oscila entre los siglos IV y III a.C.

Finalmente, en lo que respecta a nuestra $\mathrm{Va}$ riante $\mathrm{E}$ constituye, como ya se indicó, una imitación indígena de los llamados «platos de pescado», de tradición ática. Se corresponden con la Forma 10eB de Aranegui y Pla (ARANEGUI, PLA, 1979, 77) y con la P6B de Cuadrado (CUADRADO, 1972, 144, Tabla XXVI), constatándose, por ejemplo, en

(21) Uno de nuestros principales problemas a la hora de sistematizar morfológica y cronológicamente algunos de los tipos que integran este Grupo, ha residido en su falta total de contexto arqueológico y en la perduración de muchas de estas formas desde casi la generalización del torno en la Península hasta época romana. Por todo ello, nuestro estudio no tratará sino de realizar una aproximación al problema y, en este sentido, proponer unos límites cronológicos que en ningún caso deben ser tomados por definitivos y concluyentes.
Alhonoz (LOPEZ PALOMO, 1981, 73 ss; Forma 8-a; Fig. 24) o en El Cigarralejo (CUADRADO, 1987, tumba 147, Fig. 123,20, cronología: $125-75$ a.C.). En la zona levantina han sido objeto de una reciente sistematización, siéndoles asignada una cronología general de la primera mitad del siglo IV a.C. (PAGE, 1984, 104, Números 105-125, Fig. 17 y Fig. 18,1 a 4).

En conjunto, se trata de piezas que pueden remontarse a prototipos muy antiguos y cuya ubicación cronológica no resulta fácil. En cualquier caso, creemos que a efectos cronológicos basta con que sean adscritas a los siglos IV-III a.C., sin que debamos intentar mayores precisiones, integrándolas en ese período en el que, como ya señalamos más arriba, puede comenzar a hablarse de una vajilla ibérica como tal, aunque inspirada en modelos mediterráneos.

\section{TIPO II (Fig. 6)}

Lo integran los cuencos de tendencia semiesférica, que constituyen uno de los tipos cerámicos más comunes entre el conjunto de vasos conservados de la necrópolis de Los Collados, donde, en gran parte, serían utilizados como tapaderas. Presentan bordes redondeados o planos, a veces ligeramente apuntados, y siempre salientes, salvo en algún caso en que pueden ser más o menos rectos; galbos convexos, de tendencia semiesférica, y base con pie más o menos indicado, plano o con ónfalo bien marcado. En su mayor parte, no muestran decoración (Números C-144, 189, 192, 194, 197, 225, 226, 227, $228,229,230,231,232,238,239,240$ y 838 ), que, cuando aparece, se limita a una banda marcando la línea del labio (Números C-193 y 195). Son 19 ejemplares, que constituyen el $11,72 \%$ del total de las piezas conservadas.

Presentan una gran diversidad de tamaños; varian notablemente en cuanto a diámetro máximo y profundidad, y constituyen una forma muy extendida por toda la zona ibérica, resultando escasamente significativa en lo que a efectos cronológicos se refiere.

Uno de los ejemplares, que no podemos considerar entre los decorados (Número C-145), muestra en su base --constituye precisamente la única pieza en que ésta aparece plana-- un grafito inciso en forma de círculo reticulado que tal vez debe ponerse en relación, como posible marca de alfar, con los 
signos circulares a que $\mathrm{P}$. Paris y A. Engel aluden al hablar de las pesas de telar (PARIS, ENGEL, 1906, 75). Estos grafitos cuentan con paralelos de enorme similitud en yacimientos como Cancho Roano (MALUQUER, 1981, Figs. 21 a 25) o Cerro Redondo (Fuente el Saz del Jarama, Madrid) (BLASCO, ALONSO, 1985, 104 ss; Fig. 37). En ambos casos se fechan entre fines del siglo $\mathrm{V}$ y comienzos del siglo II a.C.

Como ya hemos indicado, la dispersión de este tipo cerámico es prácticamente general por todo el área ibérica y, aunque su cronología más habitual se suele centrar entre fines del $\mathrm{s}$. $\mathrm{V}$ y mediados del s. III, lo cierto es que perduraría durante bastante tiempo, integrándose de hecho en la propia cerámica común romana.

\section{TIPO III (Fig. 7)}

Conjunto de cuencos de gran afinidad con el tipo anterior, pero que presentan en todos los casos bordes planos, exvasados, y ausencia de pie, con bases planas, de ónfalos apenas marcados. Los galbos, convexos, son en general de tendencia semiesférica y a veces aparecen levemente carenados. Los dos ejemplares que constituyen el tipo muestran sus bases atravesadas por un orificio más o menos central que, sin duda, tuvo como objetivo principal la inutilización de los mismos. (Números C-233 y 242): Representan el $1,23 \%$ del total.

\section{Variante A:}

La consideramos como tal porque, aunque responde en esencia a las características que marcan el tipo, ofrece algunas modificaciones morfológicas que resultan suficientes para individualizarla. En concreto, se trata de un cuenco elaborado en pasta gris de gran calidad que muestra hacia la mitad de su galbo una acusada acanaladura, de efecto puramente decorativo. Su boca se prolonga formando una especie de pico de sección rectangular con bordes muy bien biselados, cuya función debió ser la de verter o tal vez la de acoger una mecha, hipótesis menos probable (Número C-246).

Estos cuencos de bordes planos y bases sin pie son también relativamente frecuentes en los yacimientos ibéricos $\mathrm{y}$, de hecho, ejemplares similares a los que nos ocupan se documentan, por ejemplo, en la necrópolis de La Bobadilla (MALUQUER, PICAZO, RINCON, 1973, Tipo I, Fig. 27); Baños de la Muela (Cástulo) (BLAZQUEZ, 1975, tumba
XVII, Fig. 116,32; Corte 10, Fig. 123,22 y 23 y Fig. 124, 24 y 26) o Cerro Macareno (PELLICER, 1982, 400, Fig. 21,4). Habitualmente, aparecen en contextos asignables al siglo IV a.C.

\section{TIPO IV (Fig. 7)}

Pequeños cuencos o páteras de borde redondeado o apuntado, siempre reentrante; galbo convexo y base con pie apenas indicado y ligero ónfalo, o pie alto, de gran esbeltez. Ofrecen una gran diversidad morfológica, atribuida por lo general a su fabricación en serie, y suelen aparecer sin decoración. Sólo en un caso ésta, de barniz rojo, cubre toda la superficie exterior.

Se conservan 8 ejemplares, que suponen el $4,93 \%$ del total.

Dintinguimos cuatro variantes -aunque, en realidad, podrían indicarse muchas más-:

\section{Variante A:}

Agrupa todas aquellas piezas de borde claramente vuelto hacia el interior, con su diámetro máximo más o menos amplio y pie bastante desarrollado, con ónfalo bien marcado (Números C-241; MAN-12.611; PA-1.294,b,c, y d).

\section{Variante B:}

Modalidad de inferior tamaño, con borde apuntado apenas entrante y con pie indicado y casi plano (Números MAN-85/56/10 y PA-1.294a).

\section{Variante $\mathbf{C}$ :}

Pieza similar a la Variante $\mathrm{A}$, respecto a la cual presenta como principales diferencias su mayor profundidad y su pie casi siempre muy desarrrollado, con alto ónfalo (Números MAN-73/66/241).

\section{Variante D:}

En líneas generales, responde a las características morfológicas del tipo, pero casi con seguridad su funcionalidad debió ser diferente. Presenta un borde redondeado y entrante; galbo de perfil troncocónico y base formando asidero y con profundo umbo interior. Aparece decorada en toda su superficie externa, incluyendo el ónfalo, y tal vez debería formar parte del Tipo I, ya que se trata de una pieza intermedia entre las Variantes $\mathrm{A}$ y $\mathrm{E}$ de aquél que, sin lugar a dudas, fue utilizada como tapadera. Aún así, hemos preferido incluirla entre las páteras de borde entrante como muestra de la amplia variedad morfológica que ésta pueden ofrecer. Responde a la Subvariante a). 

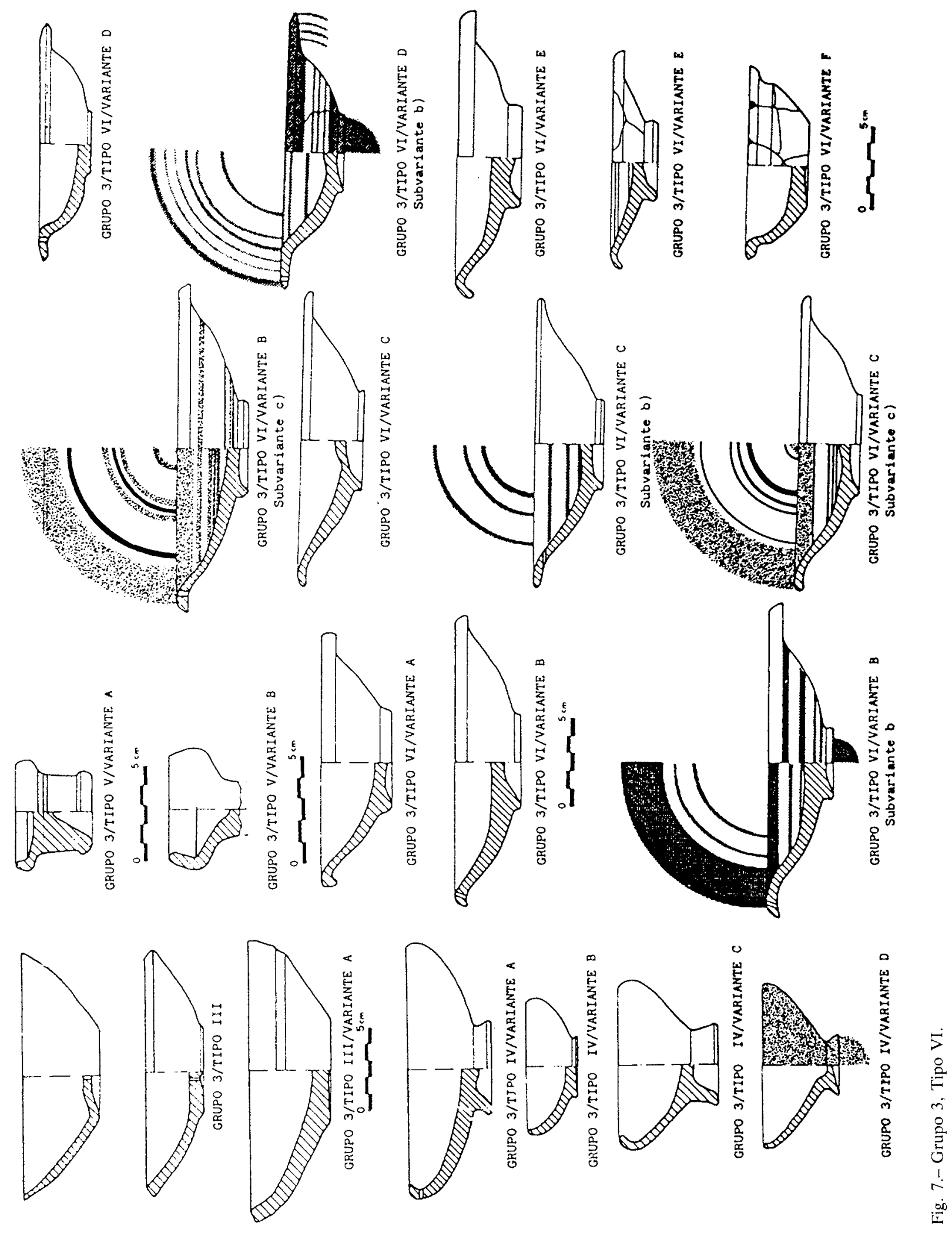
Nos hallamos ante un tipo de recipiente extraordinariamente abundante en todo el territorio ocupado por la cultura ibérica, que fue imitado de un modelo ático, siendo tal vez reinterpretado en cuanto a su funcionalidad por el mundo indígena, y que se puede considerar aceptado desde mediados del siglo IV a.C., perdurando hasta plena época romana, si bien conoce su máximo apogeo a lo largo de los siglos III y II a.C. Su presencia la podemos señalar en multitud de yacimientos, caso de Los Torviscales (material inédito); Baza (PRESEDO, 1982, tumba 19, Fig. 18,3, tumba 130, Fig. 150,5, etc.); El Higuerón (FORTEA, BERNIER, 1970, 90, Fig. 12,283); Alhonoz (LOPEZ PALOMO, 1981, 74 ss; Forma 9, Figs. 25 y 26); Tutugi (CABRE, MOTOS, 1920, Lám. XIII); La Albufereta (RUBIO GOMIS, 1986, tipo A, Fig. 134,A y Tipo B, Fig. 134,C) o el Cigarralejo (CUADRADO, 1972, 144-45, Formas P-7 y P-8, Tablas XXVI a XXVIII; 1987, tumba 54, Fig. 59,10,13 y 15; tumba 59, Fig. 64,1,2, a y 2 b).

\section{TIPO V (Fig. 7)}

Piezas de muy escaso tamaño, con bordes redondeados, rectos o ligeramente entrantes, y galbo de tendencia convexa, a veces casi inexistente, que da paso a una base con pie muy desarrollado, alto ónfalo e incluso umbo interior. No presentan decoración y resultan especialmente frecuentes en zonas de hábitat.

Dintinguimos dos variantes:

\section{Variante A:}

Borde redondeado y casi recto que en realidad se prolonga hasta la base, dado que el galbo se puede considerar inapreciable; base plana, con alto pie recto, labiado al exterior, y ónfalo muy pronunciado. La única pieza constatada procede al parecer del poblado del Cerro de la Cruz y carece de decoración.

\section{Variante B:}

Borde redondeado y entrante; breve galbo de tendencia bitroncocónica, que se prolonga en un alto pie sólo en parte conservado. En el interior, la base remata en un profundo umbo de tendencia cónica.

El único ejemplar documentado entre el material antiguo aparece muy erosionado y no muestra huellas de decoración pintada.

Los recipientes de este tipo, del que apenas hemos encontrado paralelos formales, han sido interpretados habitualmente como «saleros» y pueden relacionarse con la Forma $7 \mathrm{~dB}$ de Aranegui y Pla, que ellos denominan «platos de pie alto» (ARANEGUI, PLA, 1979, 76 y 81). En esencia, se desconoce su funcionalidad concreta, aunque a nuestro juicio deben interpretarse en función de alguna sustancia de indudable estimación, no necesariamente alimenticia, y como creación propia de la cerámica indígena, pudiéndose incluir en ese fenómeno de proliferación de la vajilla de uso particular que se constata a partir de mediados del siglo IV a.C.

\section{TIPO VI (Fig. 7)}

Conjunto de piezas muy diversas que, si bien en líneas generales responden a un modelo relativamente común, muestran una cierta heterogeneidad formal que permite agruparlas en varios lotes bastante uniformes.

Se trata de platos, utilizados sin duda en ocasiones como tapaderas, de borde labiado, redondeado o apuntado, vueltos, oblícuos, de tendencia horizontal e incluso en visera; galbo de perfil convexo, a veces carenado, y base por lo cumún con pie indicado y ónfalo más o menos alto, aunque existen excepciones. Aparecen decorados con cierta frecuencia, mostrando en todos los casos un esquema compositivo de bandas concéntricas que responden a las categorías monócroma y polícroma, es decir, correspondientes a las Subvariantes b) y c).

Se conservan 18 ejemplares, que suponen el $11,11 \%$ del total. Presentan decoración en 9 casos, sólo en tres de ellos polícroma.

Distinguimos seis variantes:

Variante A:

Entre el material antiguo aparece integrada por un solo ejemplar de borde labiado en forma de cabeza de ánade, exvasado hasta resultar casi horizontal, galbo de perfil convexo y base con pie y ónfalo indicados.

\section{Variante B:}

Platos más o menos profundos, de bordes apuntados y vueltos, galbo de perfil convexo, en ocasiones con una ligera carena marcando el hombro, y base con pie indicado y ónfalo. En su mayoría presentan dos orificios de suspensión bajo el borde $\mathrm{y}$, aunque aparecen ejemplares sin decoración (Números C-245 y MAN-85/56/12), tres de ellos ofrecen ambas superficies cubiertas por un sistema de bandas paralelas, monócromas (Números C-244 y 250) o polícromas (Número C-234), por lo que responden a las Subvariantes b) y c). En el número 250 
la decoración se extiende además al ónfalo, lo que da pie a interpretarlo como tapadera.

\section{Variante C:}

En su esquema formal resulta prácticamente idéntica a la variante anterior, con las únicas diferencias de que sus bordes son redondeados y en algún caso su ónfalo aparece bastante desarrollado, marcándose con claridad en el interior. Presenta también, a veces, orificios de suspensión y hombro insinuado y ofrece tanto ejemplares sin decoración (MAN. Números 85/56/13) como profusamente decorados, siempre mediante bandas concéntricas, monócromas (Números C-235 y 190) o polícromas (MAN. Número 85/56/3).

\section{Variante D:}

Agrupa una serie de piezas de borde redondeado o ligeramente apuntado y siempre de tendencia horizontal, marcando su diferenciación del cuerpo mediante una acusada carena interior. Galbo de perfil convexo y base con pie indicado y ónfalo, salvo en un vaso en que aparece plana. Se dan tantos casos no decorados (Números C-256 y 836), como integrables en la Subvariante b (Números C-252, MAN. 12.606), es decir, con decoración a bandas monócromas que en ambos ejemplares cubre sus dos superficies, extendiéndose al ónfalo en uno de ellos.

\section{Variante E:}

Constituye un modelo formal muy similar a la Variante D y a la vez relacionable con otras anteriores. Son piezas de borde redondeado sencillo que se vuelve hasta casi tomar una dirección vertical; galbo de perfil convexo, que en algunas marca una suave carena hacia su mitad, y base con pie indicado y alto ónfalo. Los dos ejemplares conservados entre el material antiguo carecen de decoración.

\section{Variante F:}

Aparece representada por una pequeña pátera de corto borde horizontal, apenas engrosado, que se diferencia del galbo mediante una pronunciada carena interior y, a su vez, hombro marcado por el exterior. La base, casi plana, presenta un ligerísimo ónfalo.

La única pieza documentada no muestra huellas de decoración pintada (Número C-248).

En su conjunto, el origen de estas formas se puede fijar en el que Belén y Pereira clasifican entre las primeras cerámicas pintadas andaluzas como Tipo 1.1.A.1: vaso en forma de casquete esférico, con borde exvasado más o menos ancho y fondo de pie indicado que, por analogías de funcionalidad, designamos como «plato». Su apa- rición debe ser puesta en relación con los prototipos de barniz rojo (BELEN, PEREIRA, 1982, 309 ss). Son piezas que, por lo tanto, tienen un origen común, pero que después se diversifican dando lugar a gran cantidad de variables locales. Este hecho dificulta su estudio comparativo, dada la larga perduración de algunas de las formas y la escasa diferenciación morfológica entre varias de ellas, e impide fijar límites cronológicos precisos.

Se trata de un conjunto de piezas que nos confirman de nuevo la riqueza formal de la vajilla ibérica y que, globalmente, pueden fecharse a lo largo del siglo IV, si bien debe admitirse su perduración durante el siglo III e incluso el s. II a.C.

\section{TIPO VII (Fig. 8)}

Platos de barniz rojo, de fabricación indígena. Presentan borde redondeado, exvasado; galbo de tendencia cóncavo-convexa, que da paso mediante una carena más o menos prununciada a la base, plana, ligeramente convexa o con pie indicado y en todos los casos con ónfalo. Suelen presentar ambas superficies cubiertas de un espeso barniz o engobe de tonos vinosos o achocolatados, acabado mediante bruñido o espatulación, si bien en algún ejemplar la decoración afecta tan sólo a la superficie interior, donde se dispone mediante un sistema de bandas concéntricas de diferente anchura.

Distinguimos dos variantes:

Variante A:

Borde redondeado, exvasado y más o menos vuelto, en dos ocasiones con orificio doble de suspensión; galbo de perfil cóncavo y carena bastante baja, hasta el punto de que a veces se identifica con el arranque de la base. Ésta suele aparecer plana o bien con cierta convexidad, siempre dotada de ónfalo. Todos los ejemplares conocidos aparecen cubiertos por un espeso barniz de gran calidad, que tan sólo deja en reserva la base de apoyo exterior y que habitualmente muestra acabados muy conseguidos, logrando un aspecto lustroso de gran belleza (Números C-198 y MAN. 12.196, 85/56/2 y $85 / 56 / 11$ ).

\section{Variante B:}

Borde redondeado, exvasado; galbo de perfil cóncavo-convexo, con carena central y base con el pie levemente indicado y ónfalo pronunciado. En este ejemplar la decoración, también de barniz ro- 


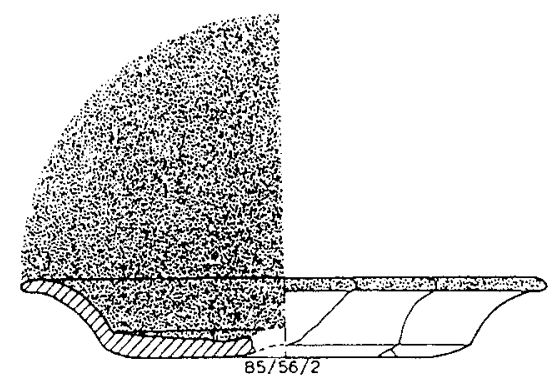

GHUPO S/TIPU VTE/VARIAITEA A

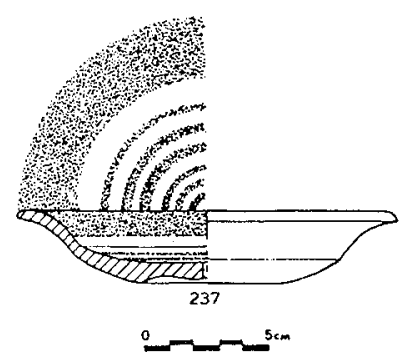

GRUPO 3/ TIPO VII/VARIANTE B
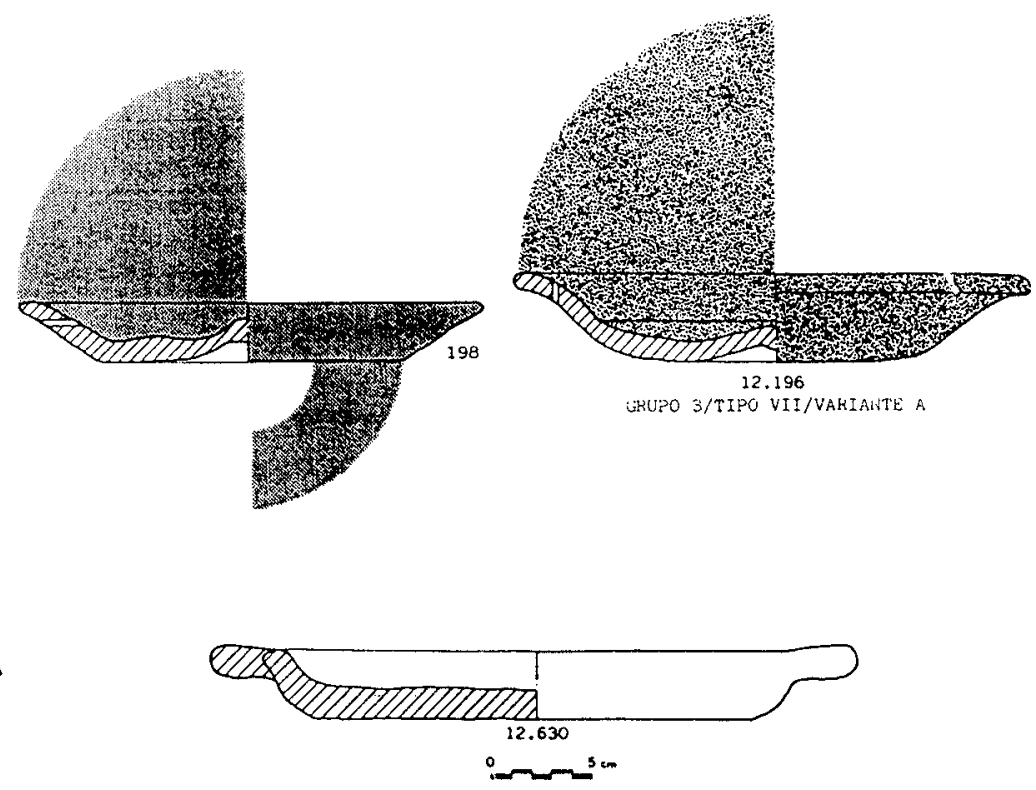

GRUPO 3/TIPO VIII

Fig. 8.- Grupo 3, Tipos VIl y VIII.

jo, afecta tan sólo a la superficie interior, disponiéndose en seis estrechas bandas concéntricas limitadas por una exterior de mucha mayor anchura.

En ambos casos se trata de vasos que responden a la Forma 1 de E. Cuadrado, asignable cronológicamente a fines del siglo V-siglo IV a.C. (CUADRADO, 1966, 37-38) y que resultan bastante comunes en yacimientos de Plena Epoca Ibérica, tales como Los Torviscales (VAQUERIZO, 1986, Fig. 2,14 y 15); Castellones de Ceal (BLANCO, 1963, Fig. 6,10c y 10d); Toya (CABRE, 1925, 88, Fig. 18); El Higuerón (FORTEA, BERNIER, 1970, Nivel III de la 2-V, Fig. 24,421; 2 VI CARA EXTERNA, Fig. 49,610 ) o El Cigarralejo (CUADRADO, 1987, tumba 49, Fig. 54,9; 59, Fig. 64,13; Fig. 176,4; о 229, Fig. 177,2).

\section{TIPO VIII (Fig. 8)}

Pátera de gran diámetro y elaboración muy tosca. Presenta borde redondeado, exvasado, galbo prácticamente inexistente, de perfil convexo, y base plana. Paredes muy gruesas y doble asa, de sección más o menos rectangular, que apoyan en la misma línea del borde. El único caso conservado aparece decorado (MAN. Número 12.630).
Si bien en un principio dudamos de su inclusión entre la cerámica de época ibérica, nuestras dudas se resolvieron al constatar varios paralelos formales de gran similitud en El Amarejo; se trata de piezas elaboradas a mano, pero muy semejantes a la que nos ocupa, presentando como única diferencia una mayor profundidad y la perforación vertical de sus asas. Broncano y Blázquez reconocen que se trata de una forma bastante rara y sugieren que, en su caso, debieron servir para contener líquidos, ya que en una de ellas aparece insinuado un pico vertedor. No se especifica con exactitud su cronología, pero la general del yacimiento se fija entre al menos el siglo IV y comienzos del II a.C. (BRONCANO, BLAZQUEZ, 1985, 191, Fig. 101, especialmente número 161; Lám. XIV, 1).

En definitiva, presentamos en este trabajo el material cerámico de época ibérica que, según los datos disponibles, procede de las necrópolis anejas al poblado localizado en el Cerro de la Cruz. Dicho material constituye un conjunto de extraordinaria entidad cuya cronología puede fijarse entre fines del s. V y al menos mediados del s. III a.C. Todo ello partiendo de las enormes limitaciones que suponen la no conservación de la totalidad de los datos y la ausencia de toda referencia acerca de su relación contextual. 


\section{BIBLIOGRAFIA}

ABAD CASAL, L. (1983): «Un conjunto de materiales de la Serreta de Alcoy», Lucentum II, Univ. de Alicante, pp. 173-199.

ALMAGRO BASCH, M. (1953): Las necrópolis de Ampurias, 2 vols., Barcelona.

ALMAGRO GORBEA, Ma J. (1984): La Necrópolis de Baria (Almería) Campañas de 1975-78, E.A.E. 129, Min. de Cultura, Madrid.

ALMAGRO GORBEA, M. (1969): La Necrópolis de Las Madrigueras, Carrascosa del Campo (Cuenca), B.P.H. X, Madrid.

- (1982): «Tumbas de cámara y cajas funerarias ibéricas. Su interpretación socio-cultural y la delimitación del área cultural ibérica de los bastetanos», En Homenaje a Conchita Fernández Chicarro, Min. de Cultura, Madrid, pp. 249-259.

ARANEGUI, C. (1970): «Cerámica ibérica de La Serreta (Alcoy): Los platos», P.L.A.V. 10, pp. 107-123.

- (1975): «La cerámica gris monócroma. Puntualizaciones sobre su estudio» P.L.A.V. XI, pp. 332-379.

ARANEGUI, C.; PLA, E. (1981): «La cerámica ibérica», en $L a$ Baja Época de la Cultura Ibérica, Actas X Aniv. de la A.E.A. de la Arqueología, 1979, Madrid, pp. 73-117.

ASTRUC, M. (1951): La Necrópolis de Villaricos, Informes y Memorias 25, Madrid.

AUBET, M ${ }^{a}$ E. (1976): La cerámica púnica de Setefilla, Studia Archaeologica 12, Univ. de Valladolid.

BELEN, M. (1982): «Tumbas prerromanas de incineración en la Necrópolis de Carmona (Sevilla)», En Homenaje a Conchita Fernández Chicarro, Min. de Cultura, Madrid, pp. 269 ss.

BELEN, P.; PEREIRA, J. (1982): «Las cerámicas pintadas a torno en Andalucía durante los siglos VIII-VI a.C.», Symposium sobre Colonizaciones, C.S.I.C, Madrid, pp. 307-360.

BELTRAN LLORIS, M. (1976): Arqueología e historia de las ciudades antiguas del Cabezo de Alcalá de Azaila (Teruel), Zaragoza.

BLANCO, A. (1959): «Excavaciones arqueológicas en la provincia de Jaén», B.I.E.G., Año VI, n 22 , Jaén, pp. 89 ss.

- (1960): «Orientalia II», A.E.Arq. XXXIII, pp. 3-44.

- (1963): «Tarros de cerámica ibérica andaluza», Oretania, Año V, $\mathrm{n}^{\circ}$ 14-15, Linares (Jaén), pp. 87-99.

- (1965): «El ajuar de una tumba de Castulo», Oretania, Año VII, $\mathrm{n}^{\circ} 19$.

BLASCO, $\mathrm{M}^{\mathrm{a}}$ C.; ALONSO, $\mathrm{M}^{\mathrm{a}}$ A. (1985): Cerro Redondo. Fuente el Saz del Jarama, Madrid, E.A.E. 143, Min. de Cultura. Madrid.

BLAZQUEZ, J.M. (1975): Castulo I, Acta Arqueológica Hispánica 8, Madrid

BRONCANO, S.; MARTIN, A.; (1985): «La necrópolis ibérica de «El Tesorico» (Agramón-Hellín, Albacete), Not.Arq.Hisp. 20, Min. de Cultura, pp. 43-181.

CABRE, J.; MOTOS F. de (1920): La necrópolis ibérica de Tutugi (Galera, provincia de Granada), Memorias de la J.S.E.A. 25, Madrid.

CASTIELLA, A. (1977): La Edad de Hierro en Navarra y Rioja, Pamplona.

CHAPA, T.; PEREIRA, J. (1986): «La organización de una tumba ibérica: un ejemplo de la necrópolis de Los Castellones de Ceal (Jaén)», Arqueología Espacial. Coloquio sobre el microespacio 3, Teruel, pp. 369-387.
CINTAS, P. (1970): Manuel d'Archéologie punique, 2 vols., París.

CUADRADO, E. (1953): «Materiales ibéricos: cerámica roja de procedencia incierta», Zephyrus $I V$, pp. 265-310.

- (1966): «La cerámica occidental de barniz rojo y su ámbito geográfico», Atti del VI Cong. Int. de Science Preistoriche et Protoistoriche III, Roma, pp. 36-46.

CUADRADO E. (1969): «Origen y desarrollo de la cerámica de barniz rojo en el mundo tartésico,» Tartessos. V. Symp. Int. de Preh. Peninsular, Barcelona, pp. 257-290.

- (1972): «Tipologia de la cerámica fina de «EI Cigarralejo». Mula (Murcia)», Trab. de Preh. 29, Madrid, pp. 125-187.

- (1987): La Necrópolis ibérica de El Cigarralejo (Mula, Murcia), B.P.H. Vol. XXIII, C.S.I.C., Madrid.

CUADRADO DE ISASA, F. (1970): «Formas nuevas de la cerámica de barniz rojo», XII C.A.N., Zaragoza, pp. 470-477.

FERNANDEZ CHICARRO, C. (1955): «Prospecciones en términos de Hinojares y La Guardia (Jaén)», B.I.E.G., Año II, n० 6, pp. 89-98.

FERNANDEZ GOMEZ, F. (1985): «El tesoro turdetano de Mairena del Alcor (Sevilla)», Trab. de Preh. 42, pp. 149-194.

FLORIDO NAVARRO C. (1984):, «Anforas prerromanas sudibéricas», Habis 15. Univ. de Sevilla, pp. 419-437.

- (1985), «Las ánforas del poblado orientalizante i ibero-púnico del Carambolo (Sevilla)», Habis 16. Univ. de Sevilla, pp. 487-517.

FORTEA, J.; BERNIER, J. (1970): Recintos y fortificaciones ibéricos en la Bética, Salamanca.

GARCIA, J.M.; INIESTA, A. (1983): «Aproximación a la cerámica de barniz rojo íbero-tartésica en la región de Murcia», XVI C.A.N., Zaragoza, pp. 561-573.

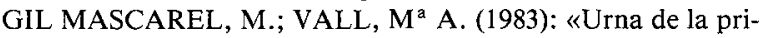
mera Edad del Hierro procedente de «Los Villares» (Caudete de las Fuentes, Valencia)», XVI C.A.N., Zaragoza, pp. 451-463.

GONZALEZ NAVARRETE, J. (1967): «Museo de Jaén», B.I.E.G., Año XIII, $\mathrm{n}^{\circ} 52$.

GONZALEZ PRATS, A. (1983): Estudio arqueológico del poblamiento antiguo de la Sierra de Crevillente (Alicante), Anejo I de la Rev. Lucentum, Univ. de Alicante.

GRIÑO, B. de; OLMOS, R.; SANCHEZ, C. (1984): «Comentarios y addenda al Catálogo», en «Discusión crítica al libro de Virginia Page Imitaciones de influjo griego en la cerámica ibérica de Valencia, Alicante y Murcia», Iberia Graeca, 1, Madrid, pp. 331-345.

JANNORAY, J. (1949): Las recientes excavaciones en la necrópolis de Ensèrune (Languedoc)", IV C.A.S.E., Cartagena, pp. 331-345.

JULLY, J.J. (1975): «Koiné commerciale et culturelle phenicopunique et ibero-languedocienne à Mediterrannée Occidentale à L'Age đu Fer», A.E. Arq. 48, pp. 22-119.

JULLY, J.J.; NÖRDSTROM, C. (1972): «Une forme de céramique ibero-languedocienne: La jarre bitroncoconique», Arch. de Preh. Lev., Vol. XIII, Valencia, pp. 93-103.

LOPEZ PALOMO, L.A. (1981): «Alhonoz»: (Excavaciones de 1973 a 1978)», Not. Arq. Hisp. Min. de Cultura, Madrid, pp. 33-189.

LUZON, J.M. (1973): Excavaciones en Itálica. Estratigrafia en el Pajar de Artillo (Campaña 1970), E.A.E. 78, Min. de Ed. y Ciencia, Madrid. 
MALUQUER, J. (1981): El santuario protohistórico de Zalamea de la Serena, Badajoz 1978-1981, P.I.P. IV, Univ. de Barcelona.

MALUQUER, J.; PICAZO, M.; RINCON, M. ${ }^{a}$ A. (1973): $L a$ necrópolis ibérica de La Bobadilla, (Jaén), P.I.P., Univ. de Barcelona.

MARAVER, L. (1867 a): «Descubrimientos arqueológicos en Almedinilla, Rev. de Bellas Artes e Histórico-Arq., Serie II, t.II, pp. 9-10.

- (1987b): «Expedición arqueológica a Almedinilla» Rev. de Bellas Artes e Histórico-Arq., Serie II, t.II, pp. 307-323.

MARCOS, A.; VICENT, A. M. a (1983-84): «La Necrópolis Ibero-Turdetana de Los Torviscales, Fuente Tójar», en $\mathrm{No}$ vedades de Arqueología Cordobesa. Exposición «Bellas Artes 83", Min. de Cultura, Madrid, pp. 11-23.

NIETO, G.; SANCHEZ, J.; POYATO, M. ${ }^{a}$ C. (1982): Oreto $I$, E.A.E. 114, Min. de Cultura, Madrid.

OLMOS, R. (1982): «Vaso griego y caja funeraria en la Bastetania ibérica», en Homenaje a Conchita Fernández Chicarro, Min. de Cultura, Madrid, pp. 259-268.

PAGE DEL POZO, V. (1984): Imitaciones de influjo griego en la cerámica ibérica de Valencia, Alicante y Murcia, Iberia Graeca. Serie Arqueológica-1, Madrid.

PARIS, P.; ENGEL, A. (1906): «Fouilles et recherches à Almedinilla (Province Cordoue)», Revue Archéologique VII, París, pp. 49-92.

PELLICER, M. (1969): «Las primeras cerámicas a torno pintadas andaluzas y sus problemas», Tartessos. V. Symp. Int. de Preh. Peninsular, Barcelona, pp. 291-310.

- (1978): «Tipología y cronología de las ánforas prerromanas del Guadalquivir, según el Cerro Macareno (Sevilla)», $\mathrm{Ha}$ bis 9, pp. $365-401$

- (1982): «Las cerámicas del mundo fenicio en el Bajo Guadalquivir, evolución y cronología según el Cerro Macareno (Sevilla)", Phönizier in westen, Mainz am Rhein, pp. 371-403.

PELLICER, M.; ESCACENA, J. L.; BENDALA, M. (1983): El Cerro Macareno, E.A.E. 124, Min. de Cultura, Madrid.
PEREIRA, J. (1979): «La cerámica ibérica procedente de Toya (Peal de Becerro, Jaén) en el Museo Arqueológico Nacional», Trab. de Preh. 36, pp. 289-347.

PEREIRA, J. (1983): «Imitaciones ibéricas de vasos áticos en Andalucía», Simposio sobre la Colonización Griega en la Península Ibérica, Barcelona.

PLA BALLESTER, E. (1980): Los Villares (Caudete de las Fuentes, Valencia), S.I.P., Serie de Trab. Varios n. ${ }^{\circ} 68$, Villencia.

PRESEDO, F. (1982): La Necrópolis de Baza, E.A.E. 119, Min. de Cultura, Madrid.

RADDATZ, K. (1969): Die schatzfunde der Iberischen Halbinsel vom ende des Dritten bis zur Mitte des Ersten Jahrhunderts vor Chr. Geb. Untersuchugen zur Hispanischen Toreutik. 2 vols. Madrider Forschungen 5, Berlín.

RIBERA, A. (1982): Las ánforas prerromanas valencianas (fenicias, ibéricas y púnicas) S.I.P., Serie de Trab. Varios n. ${ }^{\circ}$ 73, Valencia.

RUBIO GOMIS, F. (1986): La Necrópolis Ibérica de La Albufereta de Alicante (Valencia, España), Serie Arqueológica n. ${ }^{\circ} 11$, Valencia.

RUIZ, A.; NOCETE, F (1981): «Un modelo sincrónico para el análisis de la producción de cerámica ibérica estampillada del Alto Guadalquivir», Cuad. de Preh. de la Univ. de Granada, 6. pp. 355-381.

SANCHEZ JIMENEZ, J. (1943): Memoria de los trabajos realizados por la Comisaría Provincial de Albacete en 1941 , Informes y Memorias n. ${ }^{\circ}$ 3, Madrid.

SANTOS VELASCO, J.A. (1983): «La denominada necrópolis ibérica de Orán, en el Museo Arqueológico Nacional», Trab. de Preh. 40, pp. 302-352.

SOLIER, Y. (1976-78): «La culture ibero-languedocienne aux VI-e -V-e siècles»), Ampurias 38-40. Simposi Int. Els Origens del món ibéric, Barcelona, pp. 211-264.

VAQUERIZO, D. (1986): «Ajuar de una tumba indígena, procedente de la necrópolis de Los Villalones, en Fuente Tójar (Córdoba)», Arqueología Espacial. Coloquio sobre el microespacio, 3, Teruel, pp. 349-367. 